\title{
Herbicide Exposure and Toxicity to Aquatic Primary Producers
}

\author{
J. Arie Vonk (D) and Michiel H. S. Kraak
}

\section{Contents}

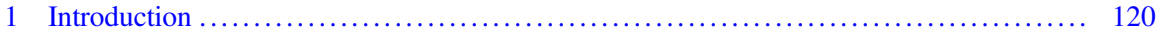

2 Exposure of Aquatic Primary Producers to Herbicides .......................... 121

2.1 Sources of Herbicides in the Aquatic Environment ........................ 122

2.2 Fate of Herbicides in the Aquatic Environment ........................... 123

2.3 Concentrations of Herbicides in the Aquatic Environment .................... 125

2.4 Bioavailability of Herbicides to Aquatic Primary Producers .................... 128

2.5 Uptake of Herbicides by Aquatic Primary Producers ........................ 130

3 Toxicity of Herbicides to Aquatic Primary Producers ........................... 133

$3.1 \quad$ Mode of Action of Herbicides ........................................ 133

3.2 Standardized Toxicity Tests with Aquatic Primary Producers .................. 134

3.3 Selected Endpoints in Standardized Toxicity Tests with Aquatic Primary Producers 136

3.4 Sensitivity of Aquatic Primary Producers to Herbicides ...................... 138

3.5 Mixture Toxicity of Herbicides to Aquatic Primary Producers ................. 150

4 Retrospective Site-Specific Risks Assessment of Herbicides for Aquatic Primary

Producers ............................................................. 152

4.1 Risk Assessment of Aqueous Herbicides for Aquatic Primary Producers ......... 153

4.2 Risk Assessment of Sediment-Associated Herbicides for Aquatic Primary Producers 155

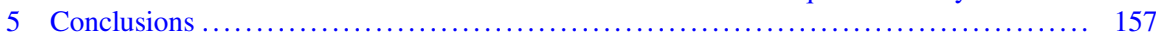

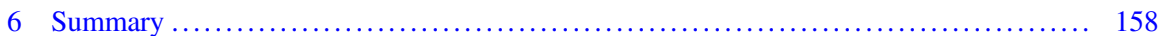

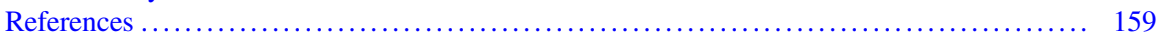

\section{Abbreviations}
AF Assessment factor
EC50 Median effect concentration
ECx Calculated concentration at which $\mathrm{x} \%$ of the tested species are affected

Electronic Supplementary Material: The online version of this chapter (https://doi.org/10.1007/ 398_2020_48) contains supplementary material, which is available to authorized users.

\footnotetext{
J. A. Vonk (ه) • M. H. S. Kraak

Department of Freshwater and Marine Ecology, Institute for Biodiversity and Ecosystem

Dynamics, University of Amsterdam, Amsterdam, The Netherlands

e-mail: j.a.vonk@uva.nl; m.h.s.kraak@uva.nl

(C) The Author(s) 2020

P. de Voogt (ed.), Reviews of Environmental Contamination and Toxicology,

Volume 250, Reviews of Environmental Contamination and Toxicology, Volume 250,

https://doi.org/10.1007/398_2020_48
} 
$\mathrm{K}_{\mathrm{OC}} \quad$ Organic carbon-water partitioning coefficient

$\mathrm{K}_{\mathrm{OW}}$ Octanol-water partition coefficient

LC50 Median lethal concentration

SSD Species sensitivity distribution

\section{Introduction}

Herbicides are the most used pesticides in North America and in Europe, and accordingly, herbicides are the most frequently detected pesticide group in North American and European surface waters (Moschet et al. 2014; Booij et al. 2015; Lopez et al. 2015; Schreiner et al. 2016). Herbicides are often well soluble in water to increase the systemic uptake by plants. This increases the chances of transport and discharges into water, and consequently, a wide variety of herbicides often exceed environmental quality standards (EQS) and regulatory acceptable concentrations (RACs) in European surface waters (Moschet et al. 2014; Schreiner et al. 2016; Casado et al. 2019). Hence, herbicides are expected to have a significant effect on aquatic ecosystem functioning (Moschet et al. 2014; Knauer 2016; Schreiner et al. 2016). Herbicides are often phytotoxic to non-target aquatic organisms such as algae and macrophytes, and these adverse effects on primary producers can cascade up the food web altering community structure (DeLorenzo et al. 2001; Ralph et al. 2007; Wood et al. 2016), since algae and plants provide food and habitat for higher trophic levels (e.g. Whatley et al. 2014; Bakker et al. 2016).

Since herbicides specifically target essential processes in primary producers, all substances with a herbicidal mode of action require regulatory testing on non-target primary producers. For the USA, data on five aquatic plants are required and in Europe data on two algal species and on one to three macrophytes. Higher-tier approaches focus on the most sensitive taxonomic groups identified in tier 1 based on obligatory data requirements from regulatory testing. If macrophytes are an order of magnitude more sensitive than algae, additional tests with macrophytes are required. Still, despite the prevalence and their documented effects on primary producers, herbicides remain relatively understudied compared to pesticides targeting various groups of animals. More toxicity tests focus on fish and macroinvertebrates compared to tests focusing on the effects of herbicides on macrophytes and algae in the environment (Birk et al. 2012). Yet, for both marine and freshwater environments, standardized ecotoxicity tests are available for microalgae (unicellular microorganisms sometimes forming larger colonies), including the prokaryotic Cyanobacteria (blue-green algae) and the eukaryotic Chlorophyta (green algae) and Bacillariophyceae (diatoms) (OECD 2011; USEPA 2012d; Wood et al. 2016). Macrophytes (macroalgae and aquatic plants) are multicellular organisms, the latter consisting of differentiated tissues, with several species included in standardized ecotoxicity tests (Knauer et al. 2006; Feiler et al. 2014; Van Wijngaarden and Arts 2018). While macroalgae grow in the water 
compartment only, aquatic plants are divided into groups related to their growth form (emergent; free-floating; submerged and sediment-rooting; floating and sediment-rooting) and can extend from the sediment (roots, stolons and rhizomes) through the water into the air (Cronk and Fennesy 2001).

There is strong evidence that anthropogenic compounds threaten the ecological integrity and consequently the biodiversity of almost half of the water bodies in Europe, with herbicides accounting for $96 \%$ of the risks to algae (Malaj et al. 2014). The aim of the present review was therefore to give an overview of the current state of science concerning herbicide exposure and toxicity to aquatic primary producers. To this end, we assessed the open literature to address the sources and fate of herbicides in the aquatic environment, their bioavailability and subsequent uptake by algae and plants. Next, the hazard of herbicides to primary producers was assessed, including their modes of action and toxicity to algae and aquatic plants determined in the various available toxicity tests, making an inventory of reported effect concentrations. Retrospective risk assessments were performed to determine whether the presence of herbicides represented an actual risk to aquatic primary producers in various environments, including water and sediment of freshwater and marine/estuarine ecosystems.

\section{Exposure of Aquatic Primary Producers to Herbicides}

Herbicides originate from different urban and agricultural usages and are transferred to surface waters from point and diffuse sources by several transport pathways (Moser et al. 2018). Exposure of aquatic primary producers to herbicides can occur through water for all algae and aquatic plants, through air for emergent and floating plants and through sediment for rooting plants and benthic algae (Fig. 1). For phytoplankton and free-living submerged aquatic plants, water is the main medium through which they are exposed to dissolved herbicides. Resuspension of sediments contaminated with herbicides can result in the release of herbicides into the water column (Pandey et al. 2019). Resuspension can therefore also expose phytoplankton and free-living aquatic plants indirectly to herbicides accumulated in the sediment. Spraying of herbicides near emergent and floating plants can result in direct exposure to herbicides transported by wind (spray drift), while volatilization of herbicides and subsequent transport by wind (vapour drift) can also result in exposure of these aquatic plant growth forms (EFSA PPR 2015). All growth forms of aquatic plants with roots extending into the sediment are additionally exposed via this environmental compartment. Sediment exposure also occurs in macroalgae with rhizoids extending into the sediment (e.g. Characeae and Caulerpa spp.) and in microalgae living on top of the sediment (e.g. benthic autotrophic biofilms including diatoms). In this chapter we will focus on sources, fate and concentrations of herbicides in the aquatic environment leading to exposure and subsequent uptake of herbicides by aquatic primary producers through surface water and pore water. 


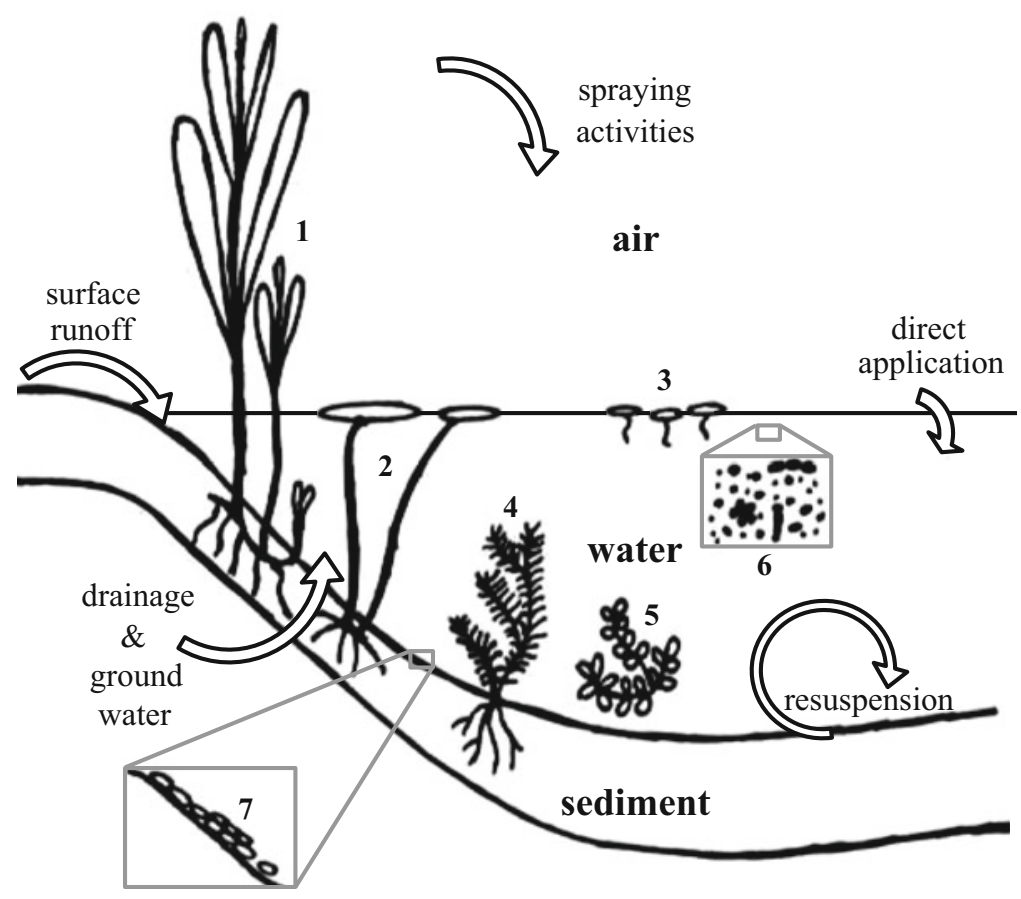

Fig. 1 Potential exposure routes to herbicides for different growth forms of aquatic primary producers through air, water and sediment from indirect sources and direct application. Growth forms depicted are [1] emergent plants, [2] rooting floating plants, [3] free-floating plants, [4] rooting submerged plants and rhizoid macroalgae, [5] free-living submerged plants, [6] phytoplankton and [7] benthic microalgae and biofilms

\subsection{Sources of Herbicides in the Aquatic Environment}

Herbicides can enter surface waters from several sources through various processes, with the main source being runoff and drainage from agricultural fields (e.g. Knauer 2016). Urban sources of herbicide pollution to surface water are wastewater treatment plants, storm sewers or combined sewer overflows and runoff from urban areas (Wittmer et al. 2010; Ensminger et al. 2013). Herbicides flow into the ditches surrounding the agricultural fields, spread over the surface waters from diffuse and point sources and drain into the groundwater. The mean annual use of herbicides in agriculture, on average $0.69 \mathrm{~kg} / \mathrm{ha}$ during $2010-2014$, is generally higher compared to use of insecticides $(0.22 \mathrm{~kg} / \mathrm{ha})$ and fungicides and bactericides together $(0.32 \mathrm{~kg} /$ ha) (Zhang 2018). Compounds ranking at the top of global herbicides use (expressed as tonnes active ingredient in 2014) are amides (38.3k), phenoxy hormone products (23.9k), bipyridyls (17.2k), urea derivatives (9.5k), dinitroanilines (6.5k), carbamate herbicides (4.0k), sulfonylureas (2.7k) and uracil (0.6k) (Zhang 2018).

New compounds are synthesized at high rates (Chemical Abstracts Service, https://www.cas.org/). However, few herbicides make it into a developed and 
registered product actually entering the market, e.g. in 2019 in Europe only approval for florpyrauxifen-benzyl. The environmental hazard and risk of new compounds have to be investigated and assessed, before any herbicide may enter the market. From a European perspective, the tier 1 data requirement always has to be fulfilled before putting an herbicide on the market. For herbicides, this includes a significant amount of information on effects on non-target plants, which is thus available from regulatory data, but often not yet from the open literature. Herbicides are often marketed as products with two to three different active ingredients. Accordingly, there will be at least some information from regulatory testing on the mixture toxicity of these active ingredients. However, application of a wide variety of herbicides by different users in a river catchment increases the potential of interactions between the active herbicides in the environment. This is especially relevant since there are additional legacies of pesticides in aquatic ecosystems, consisting of herbicides that have already been banned from the regions (e.g. triazine herbicides terbuthylazine and simazine in the EU; Rasmussen et al. 2015).

Herbicides are also directly applied in the aquatic environment to eradicate expansions of invasive aquatic plant species in various parts of the world, especially in North America, Australia and New Zealand (Lake and Minteer 2018). Invasive species targeted by herbicide application include Phragmites australis (common reed), Myriophyllum spicatum (Eurasian watermilfoil), Hydrilla verticillata (water thyme) and Eichornia crassipes (water hyacinth) (Hershner and Havens 2008; Kettenring and Adams 2011; Hussner et al. 2017). Various herbicides are used for the control of these invasive species, including glyphosate, 2,4-D, picloram, diquat and triclopyr (Kettenring and Adams 2011; Hussner et al. 2017). Often herbicide applications are combined with other management strategies, including biological controls and plant competition, although herbicide application can influence biological control through direct and indirect effects of the herbicide on other biota (Lake and Minteer 2018). Generally, herbicides need carefully timed and repeated applications, have modest success and induce significant collateral risk (Hershner and Havens 2008). Common problems associated with the application of herbicides include effects on non-target species and novel invasions following control of initial invasive species (Kettenring and Adams 2011). One solution is the application of systemic herbicides to dewatered or drawdown canals to allow herbicides to directly target the plant populations while strongly limiting the transport of the herbicide by the water (Hussner et al. 2017). Hence, the unintentional as well as intentional sources of herbicides in the aquatic environment are numerous, evidently leading to the widespread presence of herbicides, inevitably leading to the exposure of non-target primary producers.

\subsection{Fate of Herbicides in the Aquatic Environment}

The fate of herbicides in the environment is determined by the combination of (1) the chemical properties and the formulation of the pesticides, (2) the local environmental 
conditions and (3) the timing, rate and method of application (Kookana et al. 1998; Rabodonirina et al. 2015). Together, they govern the fate of herbicides in the aquatic environment by influencing retention processes (e.g. adsorption to particles and uptake by organisms), transformation processes (abiotic and biotic degradation into other (toxic) compounds), and transport processes of the herbicides. Transport of herbicides into aquatic environments is driven by runoff from nearby agricultural or other terrestrial environments, drift of herbicides along the catchment and leaching of herbicides into groundwater sources. Leaching of herbicides into groundwater is a rather negligible source of contamination in Europe, since any compound that might end up in groundwater at a concentration greater than $0.1 \mu \mathrm{g} / \mathrm{L}$ would be prohibited. Instead, in agricultural areas where drainage canals are used, relevant amounts of herbicides may be transported via drainage water into receiving aquatic ecosystems. In this way, local hydrological processes form the main drivers for the mobilization and transport of herbicides into surface water (Klaus et al. 2014). Charged and hydrophilic herbicides generally remain in the water column. However, herbicides with a higher octanol-water partitioning coefficient $\left(\mathrm{K}_{\mathrm{OW}}\right)$ are more hydrophobic and accumulate at higher rates in the sediment through sorption on clay particles and organic matter (Voice and Weber 1983).

Many herbicides interact with the dissolved and particulate organic matter in the water, resulting in the adsorption of active herbicides (Voice and Weber 1983; Chefetz et al. 2004; Pandey et al. 2019). These aggregates may sink to the bottom causing the transport of herbicides from the water column to the sediment. Accumulation of herbicides in the sediment is primarily determined by the organic carbon content of the solid and the clay-size fraction (Chefetz et al. 2004; Clausen et al. 2004) causing sediments to be the main sink for many herbicides. Furthermore, herbicides can be adsorbed or taken up by aquatic primary producers (Crum et al. 1999; Turgut 2005). Especially vascular species, like Cabomba aquatica, Eichhornia crassipes, Elodea canadensis, Lemna minor, Ludwigia peploides, Myriophyllum aquaticum and Spirodela polyrhiza, have efficient capacities to take up pesticides from the aquatic environment, leading to accumulation of herbicides at target sites (Turgut 2005; Olette et al. 2008; Anudechakul et al. 2015; Pérez et al. 2017). Reported removal rates of herbicides by phytoplankton species vary considerably, ranging from negligible or a few percent after a couple of days (Weiner et al. 2004; Chalifour et al. 2016) up to 80\% removal after 24 h (González-Barreiro et al. 2006), revealing the potential of aquatic primary producers as sink for herbicides.

Environmental conditions such as the $\mathrm{pH}$, redox and light conditions and temperature are important factors determining the degradation of herbicides in the environment. In the absence of light, degradation of herbicides can be one order of magnitude slower (Mercurio et al. 2016). Surface water $\mathrm{pH}$ can alter the charge of herbicides and the hydrolysis and degradation rates of herbicides (Schneiders et al. 1993). Degradation of herbicides is often faster at the sediment-water interface compared to the surface water (Rice et al. 2004; Mercurio et al. 2016). Degradation processes of herbicides in the sediment including hydrolysis, volatilization and microbial degradation are related to the $\mathrm{pH}$, redox conditions and temperature of the sediment (Kookana et al. 1998; Graymore et al. 2001). Especially at the interface 
between water and sediments, microbial activity is higher compared to both surface water and in the sediment. Under anaerobic conditions in aquatic ecosystems, as often present in the sediment, biodegradation is generally limited (Mercurio et al. 2016; Ghattas et al. 2017). Contrary, microbial activity is stimulated by plant exudates, resulting in higher degradation rates or accumulation of herbicides nearby roots in both the water and in the sediment (Anudechakul et al. 2015; Singh and Singh 2016). Overall, microbes are the main vehicle for remediation of herbicides in the environment (Singh and Singh 2016). Half-lives of the herbicides in aquatic ecosystems can be over 100 days, as observed by Mercurio et al. (2016) for diuron, atrazine, hexazinone and tebuthiuron. Only for metolachlor exposed under light conditions and for 2,4-D exposed in dark conditions, these authors measured halflives of less than 100 days. Metabolites of herbicides are significantly less biologically active than the parent compounds and are generally more polar and more water soluble than the parent compounds. This results in different transport behaviours between the parent herbicides and the metabolites (Boxall et al. 2004). Although, at least in Europe, the hazard and risks of the main metabolites have to be assessed in prospective risk assessments (e.g. EFSA PPR 2013, 2015), the bioavailability and mode of action of metabolites is not always known (Busch et al. 2016).

\subsection{Concentrations of Herbicides in the Aquatic Environment}

Changing and differential use has had a strong impact on the concentrations of herbicides in the aquatic environment. Nevertheless, herbicides are the main contributor to the total amount (expressed in $\mu \mathrm{g} / \mathrm{L}$ ) of pesticides present in aquatic ecosystems (Casado et al. 2019). The most frequently detected herbicides present in the highest concentrations in source waters in the USA in 1999-2000 had a photosynthesis-inhibiting mode of action (Coupe and Blomquist 2004). In a more recent study, herbicides with an auxin stimulating mode of action $(2,4-\mathrm{D}$, triclopyr and dicamba) were three of the five most frequently detected herbicides (Ensminger et al. 2013). Out of the ten most frequently used herbicides in the USA in 1999-2000 (Coupe and Blomquist 2004), only two, atrazine and simazine, were detected in streams and groundwaters in Europe in 2016 (Schreiner et al. 2016). In a recent analysis of 29 small waterways across 10 countries in the European Union, Casado et al. (2019) analysed in total 103 different pesticides, $45 \%$ of them being herbicides. Herbicides were detected in $52 \%$ of the samples, and the most frequently detected herbicides were terbuthylazine (100\% of the samples) and metolachlor $(90 \%)$. The same substances are also included in the list of the most frequently detected pesticides in the USA, Germany, France and the Netherlands compiled by Schreiner et al. (2016).

Detection of herbicides is often related to recent application on nearby fields and rain-induced runoff to adjacent aquatic ecosystems. In terms of total amount of pesticides (as ng/L) detected by Casado et al. (2019), 97\% corresponded to herbicides, which was mainly due to the outstandingly high concentrations of six 
herbicides (dimethenamid, MCPA, 2,4-D, ethofumesate, prosulfocarb and terbuthylazine) present in concentrations above $1,000 \mathrm{ng} / \mathrm{L}$ at specific sites. These six herbicides were also reported by Moschet et al. (2014) in small Swiss rivers. Concentrations of specific herbicides in surface waters are generally not very high, although a large number of different herbicides can be found. Yet, high peak values with short exposure times occur generally in small streams and ditches related to application in nearby agricultural fields and concurring runoff to these aquatic ecosystems. In larger streams and water bodies lower in the catchment, peak values of specific herbicides are lower due to dilution, while at the same time more different herbicides are present. Monitoring studies on herbicides in the aquatic environment have focused often on the water phase (e.g. Schreiner et al. 2016), while these herbicides have been detected in biota and sediments as well (e.g. Masiá et al. 2013). In fact, herbicides quickly disappear from the surface waters through absorption to the sediment, degradation into other compounds through various processes including hydrolysis and photolysis or accumulation in plants (Kookana et al. 1998; Ramezani et al. 2008; Remucal 2014). The concentrations of herbicides are related to the sediment type (organic matter, sand and clay content) (Kronvang et al. 2003), and sediments have been shown to be a sink for many anthropogenic pollutants including various herbicides. Sediments can also become sources of pesticides. Studying aquatic systems influenced mainly by urban runoff in the USA, Ensminger et al. (2013) observed that concentrations of the most frequently detected pesticides in sediments (bifenthrin and other pyrethroids) increased strongly during storm events in the water. Hence, they concluded that resuspension of sediments was a source of bifenthrin for surface waters.

Comparing herbicides in surface waters and sediments is challenging, since only a few studies present an overview of the most detected herbicides in sediments. Comparing the most frequently detected herbicides in European rivers for sediments (Massei et al. 2018) and surface waters (Schreiner et al. 2016) showed similarities as well as differences between both compartments (Table 1). The five most frequently detected herbicides in the sediment are also in the top ten of the surface waters, albeit in different order, and for terbuthylazine and atrazine, mainly their transformation products were measured in the sediment. The remaining top ten of most frequently detected herbicides were completely different for sediments and surface waters, indicating that the herbicide mixture present in both compartments differs substantially. It is therefore argued that for a complete risk assessment of herbicides, both aquatic environmental compartments, water and sediment, should be taken into consideration.

Although herbicides are also released from treated wastewater discharged from point sources (Munz et al. 2017), diffuse pollution is often the dominant source for herbicides (Moschet et al. 2014). Quantification of herbicides in streams is therefore challenging and especially demanding due to the high spatial-temporal concentration dynamics, which require large sampling and analytical efforts to obtain representative data on the actual water quality (Wittmer et al. 2010). Grab sampling generally provides only a snapshot of the herbicides present in a water body (Jones et al. 2015) and results in underestimations of concentrations, except when sampling occurred 
Table 1 The top ten most frequently detected herbicides in the surface waters and sediments of river ecosystems in Europe (rank \# in each environmental compartment) based on percentage sites at which the compound was present, analysed by Schreiner et al. (2016; surface water) and by Massei et al. (2018; sediment)

\begin{tabular}{|c|c|c|c|c|c|c|}
\hline \multicolumn{2}{|l|}{ Herbicide } & \multirow[b]{2}{*}{ MoA } & \multicolumn{2}{|c|}{ Surface water } & \multicolumn{2}{|c|}{ Sediment } \\
\hline Compound & CAS & & $\begin{array}{l}\text { Rank } \\
\#\end{array}$ & $\begin{array}{l}\% \text { Sites } \\
\text { detected }\end{array}$ & $\begin{array}{l}\text { Rank } \\
\#\end{array}$ & $\begin{array}{l}\% \text { Sites } \\
\text { detected }\end{array}$ \\
\hline Acetochlor & 34256821 & $\begin{array}{l}\text { Inhibition of cell } \\
\text { division }\end{array}$ & - & & 6 & 16.7 \\
\hline $\begin{array}{l}\text { Atrazine/2- } \\
\text { hydroxyatrazine }\end{array}$ & $\begin{array}{l}1912249 / \\
2163680\end{array}$ & $\begin{array}{l}\text { Photosynthesis } \\
\text { inhibition/? }\end{array}$ & 5 & 25.9 & 2 & 40.0 \\
\hline Bentazon & 25057890 & $\begin{array}{l}\text { Photosynthesis } \\
\text { inhibition }\end{array}$ & 8 & 22.8 & - & \\
\hline Diuron & 330541 & $\begin{array}{l}\text { Photosynthesis } \\
\text { inhibition }\end{array}$ & 2 & 46.2 & 3 & 36.7 \\
\hline Flurtamone & 96525234 & $\begin{array}{l}\text { Carotenoid bio- } \\
\text { synthesis } \\
\text { inhibition }\end{array}$ & - & & 10 & 10.0 \\
\hline Irgarol & 28159980 & $\begin{array}{l}\text { Photosynthesis } \\
\text { inhibition }\end{array}$ & - & & 7 & 13.3 \\
\hline Isoproturon & 34123596 & $\begin{array}{l}\text { Photosynthesis } \\
\text { inhibition }\end{array}$ & 1 & 51.0 & 4 & 26.7 \\
\hline MCPA & 94746 & Synthetic auxin & 3 & 36.7 & - & \\
\hline Mecoprop & 93652 & Synthetic auxin & 7 & 22.9 & - & \\
\hline Metazachlor & 67129082 & $\begin{array}{l}\text { Inhibition of cell } \\
\text { division }\end{array}$ & 9 & 22.3 & - & \\
\hline Metolachlor & 51218452 & $\begin{array}{l}\text { Inhibition of cell } \\
\text { division }\end{array}$ & 6 & 25.2 & 5 & 23.3 \\
\hline Simazine & 122349 & $\begin{array}{l}\text { Photosynthesis } \\
\text { inhibition }\end{array}$ & 10 & 21.4 & - & \\
\hline Simetryn & 1014706 & $\begin{array}{l}\text { Photosynthesis } \\
\text { inhibition }\end{array}$ & - & & 9 & 13.3 \\
\hline $\begin{array}{l}\text { Terbuthylazine/ } \\
\text { terbuthylazine-2- } \\
\text { hydroxy }\end{array}$ & \begin{tabular}{|l|}
$5915413 /$ \\
66753079
\end{tabular} & $\begin{array}{l}\text { Photosynthesis } \\
\text { inhibition/? }\end{array}$ & 4 & 29.4 & 1 & 70.0 \\
\hline Terbutryn & 886500 & $\begin{array}{l}\text { Photosynthesis } \\
\text { inhibition }\end{array}$ & - & & 8 & 13.3 \\
\hline
\end{tabular}

Modes of action (MoA) were obtained from Busch et al. (2016). (rank \# '-' means that the herbicide is not in the top ten for that environmental compartment)

during a runoff event (e.g. Casado et al. 2019). Two possible solutions are eventdriven sampling and passive sampling. The primary transport routes for pesticides to aquatic ecosystems are surface runoff and tile drainage induced by heavy precipitation events (Leu et al. 2004; Stehle and Schulz 2015). During precipitation events after pesticide application, maximum pesticide concentrations can be a factor of 10-100 higher than during base-flow conditions (e.g. Rasmussen et al. 2015). Therefore, assessing exposure by event-driven sampling following spray application outperforms the widely used automatic water sampling at fixed intervals (Lorenz 
et al. 2017). Passive sampling can overcome the limitations of grab sampling by exposing a sorbent in the aquatic environment for several weeks to months, accumulating herbicides from the water over time (Vrana et al. 2005). In this way, passive sampling integrates fluctuations in herbicide concentrations in time and simultaneously enriches surface water samples to an extent that (bio)analytical detection limits become very low (De Baat et al. 2019). Passive samplers have been successfully applied to quantify exposure to both lipophilic and more watersoluble compounds (e.g. range log $\mathrm{K}_{\mathrm{OW}}$ 0.47-4.92; Fernández et al. 2014).

Since hydrological processes are the main drivers for the mobilization and transport of pollutants into surface water (Klaus et al. 2014), key transport mechanisms for herbicides can be derived from insight into concentration and discharge dynamics at the catchment outlet (Wittmer et al. 2010). An alternative method is the event-based hysteresis analysis, regarded as a valuable tool to infer the source areas, transport mechanisms, storage and mobilization capacity of herbicides and biologically active metabolites (Tang et al. 2017). Modelling expected concentrations of herbicides in catchments can provide essential insights into the exposure of aquatic primary producers to herbicides. Moser et al. (2018) showed that key drivers and processes are reasonably well approximated by a simple model that includes land use as a proxy for herbicide use, weather data for the timing of herbicide applications and discharge or precipitation as drivers for transport. They could predict the timing and level of peak concentrations within a factor of 2 to 3 in a spatially distributed manner at the scale of large river basins. Better quantification of episodic pesticide pollution events would result in more comprehensive assessments of variations in herbicide exposure (Munz et al. 2017), and coupled progress in modelling, such as the FOCUS modelling approach, and in measuring herbicide concentrations in the field remain necessary to improve exposure assessments in aquatic ecosystems (Moser et al. 2018).

\subsection{Bioavailability of Herbicides to Aquatic Primary Producers}

The bioavailable concentration is defined as the concentration that is freely available for uptake, crossing an organism's cellular membrane from the medium the organism inhabits at a given time (Semple et al. 2004). The bioavailability of herbicides depends on the molecular characteristics of the herbicide and on environmental conditions (Landrum et al. 1996; Delle Site 2001), but is also greatly influenced by the test species and their physiology (Gomes and Juneau 2017). Furthermore, after entering the environment, bioavailability of herbicides is altered by the prevailing environmental conditions of the soil, surface waters and sediments (Delle Site 2001; Semple et al. 2013). Only by direct contact to herbicides of aquatic primary producers through nearby spraying activities (direct or wind-driven), the resulting exposure is not altered through processes influencing bioavailability of the herbicide (Lockhart et al. 1989; EFSA PPR 2015). 
Environmental conditions affecting the bioavailability of herbicides in the water column are mainly temperature, $\mathrm{pH}$ and dissolved organic matter (DOM) concentrations and quality (Landrum et al. 1996). Since herbicides generally have a low hydrophobicity $\left(\log \mathrm{K}_{\mathrm{OW}}<3\right.$ ), the impact of particles on their bioavailability is generally small (Knauer et al. 2017). Water and particle-associated concentrations of herbicides are estimated based on the organic carbon-water partitioning coefficient $\left(\mathrm{K}_{\mathrm{OC}}\right)$. As for neutral organic compounds, the $\log \mathrm{K}_{\mathrm{OC}}$ of herbicides correlates positively with the octanol-water partitioning coefficient $\left(\log \mathrm{K}_{\mathrm{OW}}\right.$ ), but for polar and ionizable herbicides, $\mathrm{K}_{\mathrm{OW}}$ is a weaker predictor of the $\mathrm{K}_{\mathrm{OC}}$ (Delle Site 2001). Also, black carbon can sorb herbicides, making them less available to primary producers (Knauer et al. 2006; Semple et al. 2013). Bioavailability of herbicides is high when they are weakly adsorbed or dissolved, in contrast to being part of more complex aggregates or when strongly bound to minerals (Eggleton and Thomas 2004).

The bioavailability of herbicides in sediments depends on a wide range of environmental conditions: sediment particle size distribution, sediment total organic carbon concentration and composition, DOM and colloid concentrations in pore water and sediment redox conditions (Landrum et al. 1996). Sorption and desorption from sediment particles under different conditions make that the exposure and bioavailability of organic contaminants in sediment is difficult to predict. The organic matrix of the sediment is competing with the organism's lipids for the available herbicide molecules (Landrum and Fisher 1998). In sediments, typically between 16 and $50 \%$ of the herbicides is bioavailable depending on the compound and characteristics of the sediment (Lamoureux and Brownawell 1999). Bioavailability of herbicides in sediments is determined by adsorption, desorption, non-extractable residue formation and biodegradation, which are all occurring interdependent and in parallel, with the latter also depending on the availability of the herbicide to organisms degrading the compounds (e.g. microorganisms) (Kanissery et al. 2019). Finally, interaction between sediment and surface water can also enhance the bioavailability of herbicides in the water. Sediment resuspension and exchange between surface water and pore water act as important emission sources for both historic-use and current-use herbicides to the water column (Cui et al. 2020).

In regulatory risk assessments, predicted concentrations for herbicides in surface waters are derived using models (e.g. European FOrum for the Co-ordination of pesticide fate models and their USe (FOCUS)), which distinguish between exposure to dissolved and particle-associated compound concentrations, because the dissolved concentration is thought to be the best predictor of bioavailability (Knauer et al. 2017). Assessment of the bioavailability of herbicides in the water column can be achieved by passive sampling, exposing a sorbent in the aquatic environment to accumulate available herbicides from the water over time (Vrana et al. 2005; De Baat et al. 2019). Characterization of the bioavailability of herbicides in the sediment can also be conducted using passive samplers, which have been developed to indirectly measure the freely dissolved concentration of compounds by chemical partitioning (e.g. Wang et al. 2018). Likewise, the ecotoxicological relevant concentration (ERC) 
in herbicide effect and risk assessment is considered to be the freely dissolved herbicide concentration in pore water and overlying water (ESFA PPR 2015).

\subsection{Uptake of Herbicides by Aquatic Primary Producers}

Aquatic primary producers take up herbicides from the water and depending on their growth form also from the air (emergent and floating plants) and from the sediment and pore water (all rooting plants, macroalgae with rhizoids and benthic algal communities). Uptake from the air is mainly the result of (intentional) spraying activities nearby aquatic ecosystems and is induced by direct contact of the herbicides dissolved in droplets with the leaves of the plants (Hussner et al. 2017). Aquatic primary producers take up herbicides directly from the surface water and sediment pore water through their cell membranes. Mechanisms for uptake of herbicides by aquatic primary producers are strongly depending on chemical properties of the herbicides. Small and nonpolar $\left(\log \mathrm{K}_{\mathrm{OW}}<1\right)$ herbicides can diffuse into the cell passively by dissolving through the membrane's hydrophobic core, driven by a concentration gradient (Hsu and Kleier 1996), while for large or strongly charged herbicides, active transport via protein transporters is needed (Ge et al. 2014). Dissolved weakly acidic herbicides penetrate the cell membranes primarily in their undissociated lipophilic form and accumulate by an ion trapping mechanism (Fahl et al. 1995). Accumulation inside the cells by ion trapping is based on the relatively low permeability of the membranes to the dissociated species (Devine et al. 1987) and differences in $\mathrm{pH}$ between surface water and cell cytoplasm. Uptake of these herbicides by aquatic primary producers is thus strongly influenced by the pH of the environment (Fahl et al. 1995; de Carvalho et al. 2007b).

Reported uptake rates of herbicides vary strongly between compounds and between aquatic primary producer species. For various species of phytoplankton, uptake rates of $1-3 \%$ of the total amount of atrazine available in the test vials have been measured over $24 \mathrm{~h}$ using ${ }^{14} \mathrm{C}$-atrazine (Tang et al. 1998; Weiner et al. 2004), while for Microcystis novacekii, an uptake rate of around $25 \%$ of the total available atrazine over $96 \mathrm{~h}$ has been reported (Campos et al. 2013). This large range in uptake rates may be due to differences in phytoplankton cell size and lipid composition (Tang et al. 1998; Tuckey et al. 2002; Weiner et al. 2004). Smaller phytoplankton cells with higher surface area-to-volume ratios will incorporate more herbicides and will be more sensitive to exposure compared to larger phytoplankton cells (Tang et al. 1998; Weiner et al. 2004). Besides cell size, also cell lipid content and composition affect the ability of algae to take up lipophilic compounds, since the presence of sterols influences the fluidity and permeability of cell membranes (Tuckey et al. 2002). In addition to cell characteristics, also environmental conditions influence the uptake of herbicides by aquatic primary producers. Temperature and light conditions alter the uptake of herbicides by phytoplankton species mainly through changes in cell size and photosynthetic activity, although responses to interactions between light, temperature and herbicides are species-specific (Gomes 
and Juneau 2017). Moreover, the uptake of herbicides by phytoplankton species can occur extremely rapid, with nearly $90 \%$ of the total uptake occurring within the first hour of exposure of the algae (Tang et al. 1998), indicating that short pulse exposures occurring after runoff or spill events can rapidly affect phytoplankton communities.

The uptake of herbicides by the roots of aquatic macrophytes occurs also fast, with various phenylureas (range $\log \mathrm{K}_{\mathrm{OW}}$ 1.0-3.7) reaching an equilibrium in Lagarosiphon major within $24 \mathrm{~h}$ of exposure (de Carvalho et al. 2007b). The uptake of herbicides by aquatic plants occurs often by partitioning of the compound over the cell membrane (Hsu and Kleier 1996). Accumulation of herbicides in aquatic plants is described well for most non-ionized compounds by equilibration into the aqueous phase in the plant cells together with partitioning onto the plant solids; however, the uptake of some herbicides (isoproturon and chlorotoluron) was better explained using solvation descriptors (de Carvalho et al. 2007b). These herbicides are taken up by specific binding at their site of action in the plant. The uptake of the herbicide isoproturon was ascribed to specific binding to the D1 protein of the photosynthetic PSII complex (Feurtet-Mazel et al. 1996). According to Knuteson et al. (2002), the age of the plant also influences the uptake rate of herbicides, since 4-week-old aquatic plants took up more simazine than 2-week-old plants. However, the tissue burden normalized for plant biomass was lower in the older plants (Knuteson et al. 2002).

Rooted aquatic plants can take up herbicides via both the roots and the leaves, with herbicide-specific differences in relative uptake rates between shoot and root (Turgut and Fomin 2002; Turgut 2005). The uptake by the roots was related linearly to the external herbicide concentrations over a wide concentration range, implying that transport across the membrane proceeds via non-facilitated diffusion (Devine et al. 1987). Briggs et al. (1982) reported a very strong relationship between the lipophilicity $\left(\log \mathrm{K}_{\mathrm{OW}}\right.$ ) of compounds and the transpiration stream concentration factor (TSCF). However, this was only applicable to emergent aquatic macrophytes, since submerged aquatic plants do not experience leaf transpiration (Turgut 2005). Still, a high $\mathrm{K}_{\mathrm{Ow}}$ value increased the uptake rate of sediment-associated herbicides via the pore water due to the high lipid content of macrophytes (Jones and Winchell 1984; Guilizzoni 1991; Cedergreen et al. 2005). In contrast, the more polar herbicides are rapidly taken up by macrophyte roots directly from the pore water (Burešová et al. 2013).

Translocation of nutrients and energy, but also other compounds, plays an important role in the exchange between shoots and roots of macrophytes. After the contact of herbicides to macrophytes has been established, they can either act as contact herbicides (e.g. diquat) and be non-mobile, i.e. only affecting the part of the organisms that it comes into contact with, or act as systemic herbicides (e.g. glyphosate and imazapyr) and be mobile, i.e. can be translocated through the organisms via the phloem or xylem (Netherland 2014). Contact herbicides only influence the plant parts directly exposed to the herbicide, like floating and emergent parts when exposed to herbicide spraying (Lockhart et al. 1989), with potential regrowth possible from non-exposed plant parts. Translocation through the plant via the phloem or xylem enables the systemic herbicides to affect all parts of the plant, 
limiting recovery or regrowth from stored resources in belowground parts. After a rapid uptake of linuron by Elodea canadensis and Myriophyllum spicatum shoots, translocation to the roots of this herbicide occurred within 1-3 days (Diepens et al. 2014a). After atrazine exposure of Hydrilla verticillata in solution, Hinman and Klaine (1992) observed that uptake and release approached equilibrium within 1 and $2 \mathrm{~h}$ for shoot and root tissue, respectively. Translocation of compounds through the plant is directly related to their water solubility (Hinman and Klaine 1992). Translocation of three analogues of phenylurea herbicides in Myriophyllum aquaticum was passive and reached optimal efficiency for herbicides with a $\log \mathrm{K}_{\mathrm{OW}}$ value of around 1.8 (de Carvalho et al. 2007a). Heine et al. (2015) developed a mechanistic model of toxicokinetic processes to predict the uptake and the elimination of herbicides, as well as the distribution processes between plant compartments (leaves, stems, roots) of M. spicatum. Their results showed that toxicokinetic patterns were mainly based on two chemical-specific parameters: the cuticular permeability and the plant/water partition coefficient.

Besides translocation of herbicides to different plant parts or cell structures, detoxification can occur after the uptake of herbicides by aquatic primary producers. Uptake by aquatic plants can accelerate degradation of the herbicide by metabolic processes (Fernandez et al. 1999; de Carvalho et al. 2007b). Glutathione-S-transferases are the main group of enzymes involved in this process by conjugating herbicides with tripeptide glutathione (Dhir et al. 2009). The biodegradation mechanism for metabolism of simazine probably involves dealkylation into hydroxysimazine followed by storage of end products in vacuoles (Knuteson et al. 2002). In this way, there is an interaction between the influence of exposure of aquatic primary producers to herbicides and the removal of herbicides by these species. Differences in sensitivity and mechanisms to deal with herbicides can therefore influence overall species composition in areas prone to herbicide exposure (Gomes and Juneau 2017).

Toxicokinetic/toxicodynamic (TKTD) models provide a conceptual framework to better understand the causes for species-specific sensitivities to a single compound, as well as the causes for different toxicities of different compounds to a single species (Ashauer and Escher 2010). TKTD models are based on the principle that processes influencing internal exposure of an organism (TK) are separated from the processes that lead to damage and effects (TD) (EFSA PPR 2018). TKTD models appear furthermore advantageous in terms of gaining a mechanistic understanding of the chemical mode of action and deriving time-independent parameters (Baudrot and Charles 2019). This is especially relevant since exposure time is an important source of uncertainty, which is associated with chemical-specific toxicokinetic and toxicodynamic characteristics (Wu et al. 2020). Different types of TKTD models have been successfully developed, including the general unified threshold model of survival (GUTS) and models for primary producers (EFSA PPR 2018; Baudrot and Charles 2019). For aquatic primary producers exposed to pesticides, TKTD models have been developed for algae, Lemna and Myriophyllum (EFSA PPR 2018). Although TKTD models are species- and compound-specific, toxicity data can be used derived from both standard test species and additional species for model 
calibrations. However, for validation of TKTD models, compound-specific and species-specific datasets from independent refined-exposure experiments are required.

\section{Toxicity of Herbicides to Aquatic Primary Producers}

\subsection{Mode of Action of Herbicides}

There is a wide diversity of herbicides that have been synthesized to attack specific biochemical targets in plants. In an attempt to classify herbicides by mode of action, a system of 22 different categories is often used (Sherwani et al. 2015). Here we present a simplified classification specifying only eight categories (Plant and Soil Sciences eLibrary 2019; Table 2). Inhibition of photosynthesis can occur through disruption of various steps in the photosynthetic process (Vonk et al. 2009). Triazine herbicides, like atrazine, simazine, metribuzin and phenylureas, like diuron, linuron and isoproturon block the electron transfer in the PSII system (Feurtet-Mazel et al. 1996; Van den Brink et al. 2006), while the herbicide isoproturon reduces the carbon fixation and oxygen production (Feurtet-Mazel et al. 1996). Plants can also repair the oxidative damage caused by photosynthesis-inhibiting herbicides, which reduces the negative effects of these herbicides (Cedergreen et al. 2005). Even a fast reversibility of photosynthesis inhibition (within hours) has been demonstrated for several photosynthesis-inhibiting herbicides (e.g. Snel et al. 1998). Plant hormonedisrupting herbicides, comprised of 2,4-D, 2,4,5-T, picloram, clopyralid and

Table 2 Classification of herbicides by mode of action

\begin{tabular}{l|l|l|l}
\hline No. & Class (mode of action) & Examples of compound groups & $\begin{array}{l}\text { Example of active } \\
\text { ingredient }\end{array}$ \\
\hline 1 & $\begin{array}{l}\text { Amino acid synthesis } \\
\text { inhibitors }\end{array}$ & $\begin{array}{l}\text { Sulfonylureas, imidazolones, } \\
\text { triazolopyrimidines, epsp synthase } \\
\text { inhibitors }\end{array}$ & Glyphosate \\
\hline 2 & Seedling growth inhibitors & $\begin{array}{l}\text { Carbamothiates, acetamides, } \\
\text { dinitroanilines }\end{array}$ & EPTC \\
\hline 3 & $\begin{array}{l}\text { Growth regulators (inter- } \\
\text { fere with plant hormones) }\end{array}$ & $\begin{array}{l}\text { Phenoxy-acetic acids, benzoic acid, } \\
\text { carboxylic acids, picolinic acids }\end{array}$ & 2,4-D \\
\hline 4 & $\begin{array}{l}\text { Inhibitors of } \\
\text { photosynthesis }\end{array}$ & $\begin{array}{l}\text { Triazines, uracils, phenylureas, } \\
\text { benzothiadiazoles, nitriles, pyridazines }\end{array}$ & Atrazine \\
\hline 5 & $\begin{array}{l}\text { Lipid synthesis inhibitors } \\
\text { Aryloxyphenoxypropionates, } \\
\text { cyclohexanediones }\end{array}$ & Sethoxydim \\
\hline 6 & Cell membrane disrupters & $\begin{array}{l}\text { Diphenyl ethers, aryl triazolinones, } \\
\text { phenylphthalamides, bipyridilium }\end{array}$ & Paraquat \\
\hline 7 & $\begin{array}{l}\text { Inhibitors of protective } \\
\text { pigments }\end{array}$ & $\begin{array}{l}\text { Isoxazolidinones, isoxazoles, } \\
\text { pyridazinones }\end{array}$ & Clomazone \\
\hline 8 & Unknown & $\begin{array}{l}\text { Compounds with proven herbicide } \\
\text { efficacy but unknown mode of action }\end{array}$ & Ethofumesate \\
\hline
\end{tabular}


triclopyr (Van den Brink et al. 2006), are especially hazardous to vascular plants, having auxin hormones that regulate their growth, in contrast to other groups of primary producers, like unicellular algae, that lack these hormones (Belgers et al. 2011). Since many of the herbicides that influence the plant hormone system are auxin stimulators, exposure to these herbicides might initially increase the growth rate of plants instead of decreasing it (Van den Brink et al. 2006).

\subsection{Standardized Toxicity Tests with Aquatic Primary Producers}

Most herbicides have been developed to be selective, i.e. to be phytotoxic to the competing non-crop plants, but not to the crop plants. This resulted in a wide variety of modes of action (Table 2). Accordingly, significant differences in toxicity to aquatic primary producer species are to be expected. Consequently, appropriate test species should be proposed, covering all presently known modes of action of the currently applied herbicides. Several standardized guidelines were proposed by organizations such as the OECD (Organisation for Economic Co-operation and Development), ASTM (American Society for Testing and Materials), USEPA (United States Environmental Protection Agency) and ISO (International Organization for Standardization), which are globally used for hazard and risk assessment. Most of these guidelines outline toxicity tests to determine the effects of hazardous herbicides on single species. For regulatory purposes, the majority of the toxicity tests are done according to freely available OECD or USEPA guidelines. However, the guidelines of the ISO and the ASTM were not freely available. Therefore, the guidelines from these organizations could not be evaluated completely, and only limited information about the species, endpoints and test methods were available. Among the standard guidelines, 18 tests consider aquatic primary producers (Table 3). In 9 of the 18 standardized guidelines with aquatic primary producers provided by the USEPA, ISO, OECD and the ASTM, the standard test species were algae, including diatoms, green algae and cyanobacteria. In five tests floating macrophytes have been selected as test organisms, all consisting of duckweed species. Submerged macrophytes have been selected in four tests and emergent macrophytes in only one test (Table 3 ). In addition, only two tests included sediment toxicity by selecting rooting plant species. Hence, among the available tests, there is a bias towards algae compared to macrophytes, while the few available macrophyte tests largely ignore the sediment as environmental compartment of concern. One reason for the relative lack of sediment tests is the usually perceived lower toxicity of herbicides in sediment tests compared to water-only tests. However, partitioning of herbicides to the sediment can result in exposure via root uptake (OECD 2014b) and enhanced toxicity in sediment tests compared to water-only tests. Hence, the paucity of tests with rooting macrophytes leaves the effect of contaminated sediments on aquatic primary producers largely unknown. Another knowledge gap concerns 


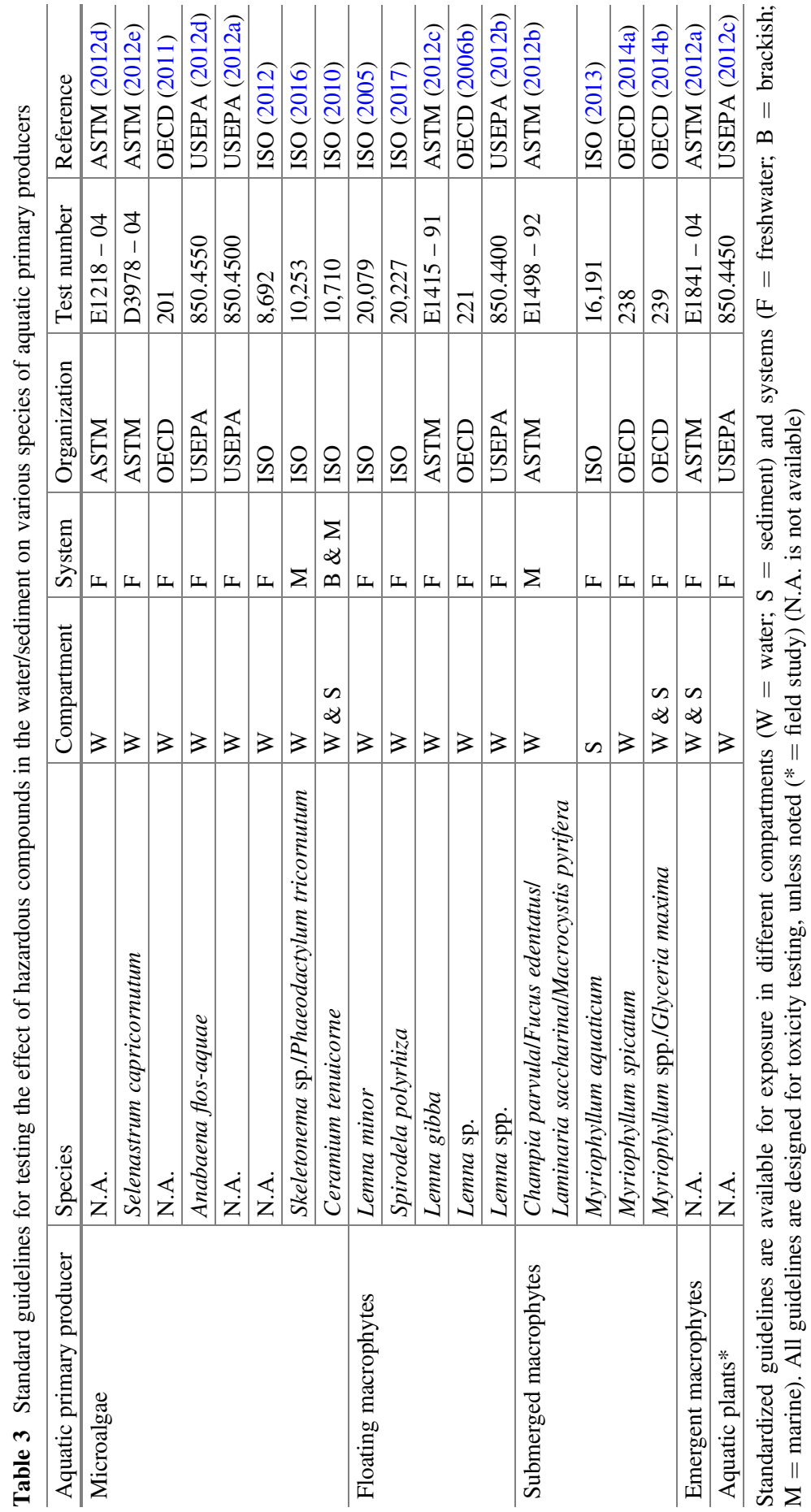


marine species that are often neglected. Only three standard guidelines were proposed to test the effects of polluted marine waters on primary producers (Table 3 ). Moreover, no standard guidelines at all were proposed to test the effect of polluted marine sediments.

Outdoor microcosms and mesocosms can be an important tool in bridging the gap between lower-tier and higher-tier laboratory studies (single-species and multispecies) and in attempting to understand, predict and confirm what may occur in the natural environment upon herbicide exposure (Coors et al. 2006; OECD 2006c). Various guidance documents have been developed for summarizing and harmonizing the results of micro- and mesocosm studies (e.g. Giddings et al. 2002; OECD 2006c; De Jong et al. 2008), because of the unique nature of each microcosm or mesocosm study in at least some aspects of the experimental design (OECD 2006c). In comparison to standardized toxicity tests, microcosm and mesocosm studies can include (1) multiple species, functional groups or habitat types, (2) more environmentally realistic exposure conditions and (3) the impact on structural and functional attributes of natural ecosystems (OECD 2006c). When studying the impact of herbicides on aquatic macrophytes, special efforts are required to establish a diverse and representative community (Giddings et al. 2002). Still, not all ecological relevant processes can be included in mesocosm studies. Due to the isolate character of mesocosms, external recovery and avoidance will not be taken into account (De Jong et al. 2008). Finally, the chosen environmental conditions in mesocosms, such as nutrient availability and substrate, can influence the effects of herbicides (cf. Dalton et al. 2015).

\subsection{Selected Endpoints in Standardized Toxicity Tests with Aquatic Primary Producers}

An obvious condition for herbicides to be effective is that they are actually taken up by the primary producers. Accumulation after uptake and translocation to specific cell organelles or plant tissue can result in increased herbicide concentrations at target sites in primary producers. Although elevated concentrations in primary producers are indicative of the presence of bioavailable herbicides, this does not necessarily imply that adverse effects on these organisms occur. Measurements assessing the accumulation of herbicides in aquatic primary producers can therefore be best combined with one or more biological endpoint assessments. The most frequently used endpoints in toxicity tests with primary producers are growthrelated effects. These endpoints are the most relevant for ecological risk assessment and are independent of the herbicides' mode of action. Other endpoints like enzyme activities or photosynthesis provide insight into the mode of action of the herbicide, but may be less relevant for ecological risk assessment. Yet, photosynthesis is the most essential metabolic pathway for primary producers, and therefore photosynthesis inhibition is the mode of action of many herbicides, whereby different steps in 
the photosynthetic pathway can be targeted. Hence, photosynthesis is relevant for assessing acute effects on the chlorophyll electron transport and can be assessed using pulse-amplitude modulation (PAM) fluorometry or from oxygen production or carbon fixation.

Growth represents the accumulation of biomass of primary producers. Growth inhibition is the most important endpoint in test with primary producers, since this endpoint integrates responses of a wide range of metabolic effects into a whole organism or a population response. However, it takes longer to assess, especially for larger primary producers. Cell counts; increase in size over time for either leaves, roots or whole organisms; and (bio)mass (fresh weight and dry weight) are the growth endpoints mostly used. Although area under the growth curve based on cell counts is a sensitive endpoint for both freshwater and marine algae (Hampel et al. 2001), assessing inhibition of growth rate is preferred over inhibition of biomass, since the latter is more affected by deviations in test conditions among studies (Bergtold and Dohmen 2011). For vascular aquatic plants, not only growth is a relevant endpoint but also endpoints specifically related to various life stages. Flowering and seed production are relevant endpoints for certain floating and emergent plant species, although vegetative reproduction is omnipresent in aquatic primary producers. Seedling emergence and early development of seedlings into plants are especially relevant for perennial and biannual aquatic plants (Muller et al. 2001). Successful germination of aquatic plants after seed dispersal can help to disperse species and to maintain healthy populations. For terrestrial plants seedling emergence tests are available (e.g. OECD 2006a; USEPA 2012e); however, no standardized seedling emergence test is currently available for aquatic plants. Other relevant endpoints for aquatic primary producers include elongation of different plant parts (e.g. roots), necrosis of leaves and disturbances in plant-microbial symbiont relationships (e.g. Mynampati et al. 2015).

Since the selected endpoint can influence the outcome of the toxicity test (Eklund and Kautsky 2003; Cedergreen et al. 2005), it is recommended to combine several endpoints in a single test. After exposure to herbicides influencing plant elongation (e.g. auxin stimulators), shoot length can be increased compared to control plants (Van den Brink et al. 2006), which is not especially beneficial to aquatic plants since this my limit their hydrodynamic resistance and further development. Growth and change in biomass or abundance are therefore generally considered to be the most robust endpoints (Knauer et al. 2006; Maltby et al. 2009; Bergtold and Dohmen 2011), showing the overall result of alterations in plant metabolic pathways by herbicides. An additional advantage is that growth can be calculated for any species, including population growth in the case of algae, facilitating the comparison of species-specific sensitivities between aquatic primary producers. Challenges to improve ecotoxicity tests with aquatic primary producers would be to include more sensitive and early response endpoints and to relate these endpoints to impact on growth, development and biomass of aquatic primary producers. Also, the development of ecotoxicogenomic endpoints (e.g. metabolomics) in the field of plant ecotoxicity tests would enable us to determine effects on a wider range of 
plant metabolic pathways. However, quantifying the effects on these metabolic pathways in terms of overall productivity of primary producers is not yet possible.

The OECD proposed growth inhibition and yield of total shoot length, fresh weight and dry weight as endpoints for a sediment-free test and additionally qualitative observations of symptoms such as chlorosis, necrosis and growth deformities for a water-sediment test with rooting macrophytes (OECD 2014a, b). For this group of primary producers, somatic endpoints like total plant length, main shoot length, fresh weight and root length are more sensitive than pigment endpoints, similar as for floating macrophytes (Hanson et al. 2003; Brain et al. 2004; Knauer et al. 2006). For soil and sediment exposure of aquatic plants to herbicides, development of endpoints related to root morphology and root metabolism could provide insights into early impact of herbicides on exposed plant parts. For auxin-type acting herbicides, root endpoints are the most sensitive somatic endpoints for rooting macrophytes (Hanson et al. 2003; Arts et al. 2008). However, development of belowground endpoints is still challenging since root development is also strongly impacted by available nutrients and redox conditions in the sediment (Barko et al. 1991; Boros et al. 2011).

\subsection{Sensitivity of Aquatic Primary Producers to Herbicides}

All herbicides are extensively tested before they can be applied in the environment. For this review, we merged the available EC50 data of aquatic primary producers used for the regulatory assessment of herbicides in Europe, mainly from the EFSA website (European Food and Safety Authority; http://www.efsa.europa.eu/; accessed Feb 2020) and from the USEPA ECOTOX knowledgebase (https://cfpub.epa.gov/ ecotox/, accessed Feb 2020). The selected herbicides were the most commonly encountered herbicides mentioned in Table 1 and supplemented with 2,4-D (CAS 94757), dicamba (CAS 1918009) and triclopyr (CAS 55335063), three commonly analysed herbicides in the environment which act as synthetic auxin growth regulators (Ensminger et al. 2013). On the EU regulatory websites, limited or no data were present for the herbicides that were not approved or even banned (atrazine, irgarol, metolachlor, simazine, simetryn and terbutryn) in Europe. From the USEPA ECOTOX database, we first selected laboratory tests on plant species with water as exposure medium (freshwater and marine) and EC50 values at the individual or the population level (abundance, (bio)mass and (population) growth rate), excluding short-term physiological endpoints like photosynthetic activity. Exposure types 'renewal' and 'flow through' as well as all EC50 values reported as 'NR' were removed. To use as much of the available data as possible, no distinction was made between nominal, initial measured and mean measured concentrations during the test. Incorrectly mentioned media types for some species (wrongly placed in either saltwater or freshwater) were corrected, and in the case of multiple EC50 values from a single combination of species and study, the average EC50 was calculated. The available effect concentrations were grouped by generic endpoint, e.g. growth 
included length, yield and biomass. Species were then divided into freshwater (§4.4.1; Supplement Table S1) and marine (§4.4.2; Supplement Table S2). For sediment-associated herbicide exposure, we searched for aquatic tests on plant species and terrestrial tests on algae, in both cases using sediment and soil as exposure medium, respectively, applying the same criteria as mentioned above.

\subsubsection{Sensitivity of Freshwater Primary Producers to Herbicides}

The inventory of the available ecotoxicity data, expressed as EC50 values with abundance, (bio)mass and (population) growth rate as endpoints, revealed that the most frequently tested herbicides were atrazine, simetryn, diuron and metolachlor, followed by irgarol, isoproturon, simazine, 2,4-D, acetochlor and MCPA (Table 4). In total, 109 freshwater taxa belonging to 66 genera were tested, the most frequently selected test genera being the algae Pseudokirchneriella (synonym of Raphidocelis, previously also classified as Selenastrum or Ankistrodesmus; www.algaebase.org) and Chlorella and the floating macrophyte Lemna. The toxicity of each herbicide varied substantially (Table 4), with the lowest effect concentration observed for irgarol $\left(\mathrm{E}_{\mathrm{b}} \mathrm{C} 500.09 \mu \mathrm{g} / \mathrm{L}\right)$ and the highest for mecoprop $\left(\mathrm{E}_{\mathrm{r}} \mathrm{C} 50729 \mathrm{mg} / \mathrm{L}\right)$. Toxicity data varied most for acetochlor, ranging from $0.0003 \mathrm{mg} / \mathrm{L}$ to $110 \mathrm{mg} / \mathrm{L}$, hence a six orders of magnitude difference, followed by atrazine, irgarol and mecoprop with a five orders of magnitude difference between the lowest and highest EC50. But also for other herbicides (2,4-D, metazachlor and metolachlor), an around four orders of magnitude difference between the highest and lowest effect concentration was not uncommon. Only for bentazon the range in effect concentrations was quite small, and these EC50 values were all relatively high $(3.88-42.5 \mathrm{mg} / \mathrm{L})$. In spite of these wide ranges in effect concentrations, we calculated the median of the available data, which allowed a general ranking of the toxicity of the herbicides. Based on median EC50 values, irgarol, terbutryn, terbuthylazine, flurtamone and simetryn were the most toxic herbicides (Table 4). On the other hand, the highest median effect concentrations were obtained for mecoprop, triclopyr, MCPA, 2,4-D and bentazon, indicating that these herbicides were the least toxic to aquatic primary producers.

Considering the species-specific sensitivities to the 18 herbicides included in our analyses, hardly any pattern was observed. Generally, the most sensitive as well as the least sensitive species differed per herbicide. Pseudokirchneriella subcapitata (=Selenastrum capricornutum) was the most sensitive and the least sensitive species for one third of herbicides (i.e. six) included in our study. Chlorella sp. was least sensitive to three herbicides, but most sensitive to isoproturon, while Anabaena flosaquae was most sensitive to two herbicides and least sensitive to one herbicide. For five herbicides, macrophytes showed the highest sensitivities, while for two herbicides, macrophytes were the least sensitive aquatic primary producers. Dividing the EC50 values obtained for aquatic primary producers into algae and macrophytes showed a large difference in available data, i.e. 456 values for algae but only 95 values for macrophytes. Consequently, most of the general patterns for aquatic primary producers described above related to the responses of algae. In fact, only for 


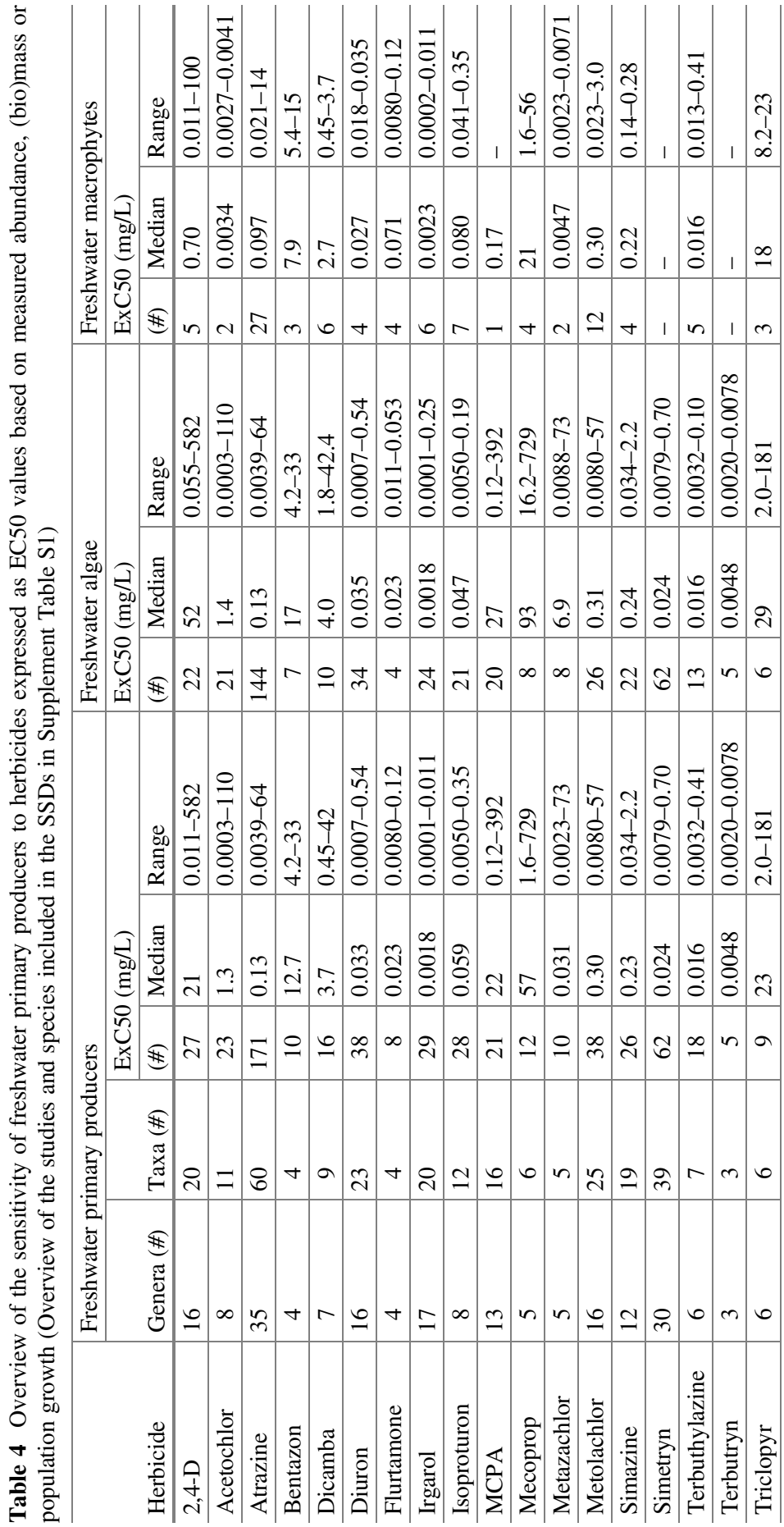


11 herbicides, at least 4 EC50 values were available for macrophytes. However, ranking these herbicides based on median EC50 values showed a similar ranking for algae and macrophytes.

The wide variety in effect concentrations per herbicide are due to species-specific sensitivities, but also due to variation in effect concentrations within the same species, among others caused by differences in exposure time between the various studies (Thompson and Couture 1991), but also on the lack of information on the used exposure metrics (nominal, measured initial or mean concentration). To distinguish these two sources of variation, effect concentrations may be best compared per herbicide and per exposure time between species. This reduces the accompanying margins of uncertainty extensively, as shown for atrazine, the herbicide for which most toxicity data are available. Generally, at a given exposure time, the maximal variability in effect concentrations for a specific herbicide per species was reduced to approximately a factor of 10 . Moreover, considering the toxicity of the herbicides per exposure time also allowed to evaluate if and how much the toxicity of the herbicides increases with increasing exposure time, although this may be masked by the use of different exposure metrices.

If enough toxicity data are available for a specific herbicide at a given exposure time, these can best be visualized and evaluated by species sensitivity distributions. A SSD is a distribution describing the variance in sensitivity of multiple species exposed to a hazardous compound. A SSD curve can be used to derive a so-called hazardous concentration on the X-axis: a benchmark concentration that can be used as regulatory criterion to protect the environment. By selecting a protection level on the Y-axis, representing a certain fraction of species affected (e.g. 5\%), one derives the compound-specific hazardous concentration 5 (HC5). The obtained EC50 values (Supplement Table S1) were combined to construct SSDs using a SSD generator (USEPA 2016). The available effect concentrations were grouped by generic endpoint, e.g. growth rate (ErC50), yield (EyC50) and biomass (EbC50). Since algal ecotoxicity data were significantly more available than macrophyte data, we first constructed SSDs based on algae. In addition, we could also construct SSDs for macrophytes for atrazine and metolachlor. An overview of the calculated HC5 concentrations for the most frequently observed herbicides per exposure time is provided in Table 5 .

For nine herbicides (acetochlor, atrazine, diuron, irgarol, isoproturon, MCPA, metolachlor, simetryn and simazine), enough ecotoxicity data (either EbC50, ErC50 or EyC50) were available to construct SSD curves for 4 days of exposure, the exposure time that had most herbicides in common (Table 5). Comparing the HC5 values derived from these SSDs allowed a clear ranking of the herbicides (Fig. 2), with irgarol being the most toxic one ( $\mathrm{HC} 50.31 \mu \mathrm{g} / \mathrm{L}$ ), followed by diuron $(0.35 \mu \mathrm{g} / \mathrm{L})$, isoproturon $(4.4 \mu \mathrm{g} / \mathrm{L})$, simetryn $(5.4 \mu \mathrm{g} / \mathrm{L})$, atrazine $(6.9 \mu \mathrm{g} / \mathrm{L})$, acetochlor $(11.0 \mu \mathrm{g} / \mathrm{L})$, simazine $(35.4 \mu \mathrm{g} / \mathrm{L})$, metolachlor $(97.3 \mu \mathrm{g} / \mathrm{L})$ and MCPA $(11.6 \mathrm{mg} / \mathrm{L})$. This ranking only partly matched the one based on the rough estimates derived from Table 4, underlining that the precise and detailed analysis of the 


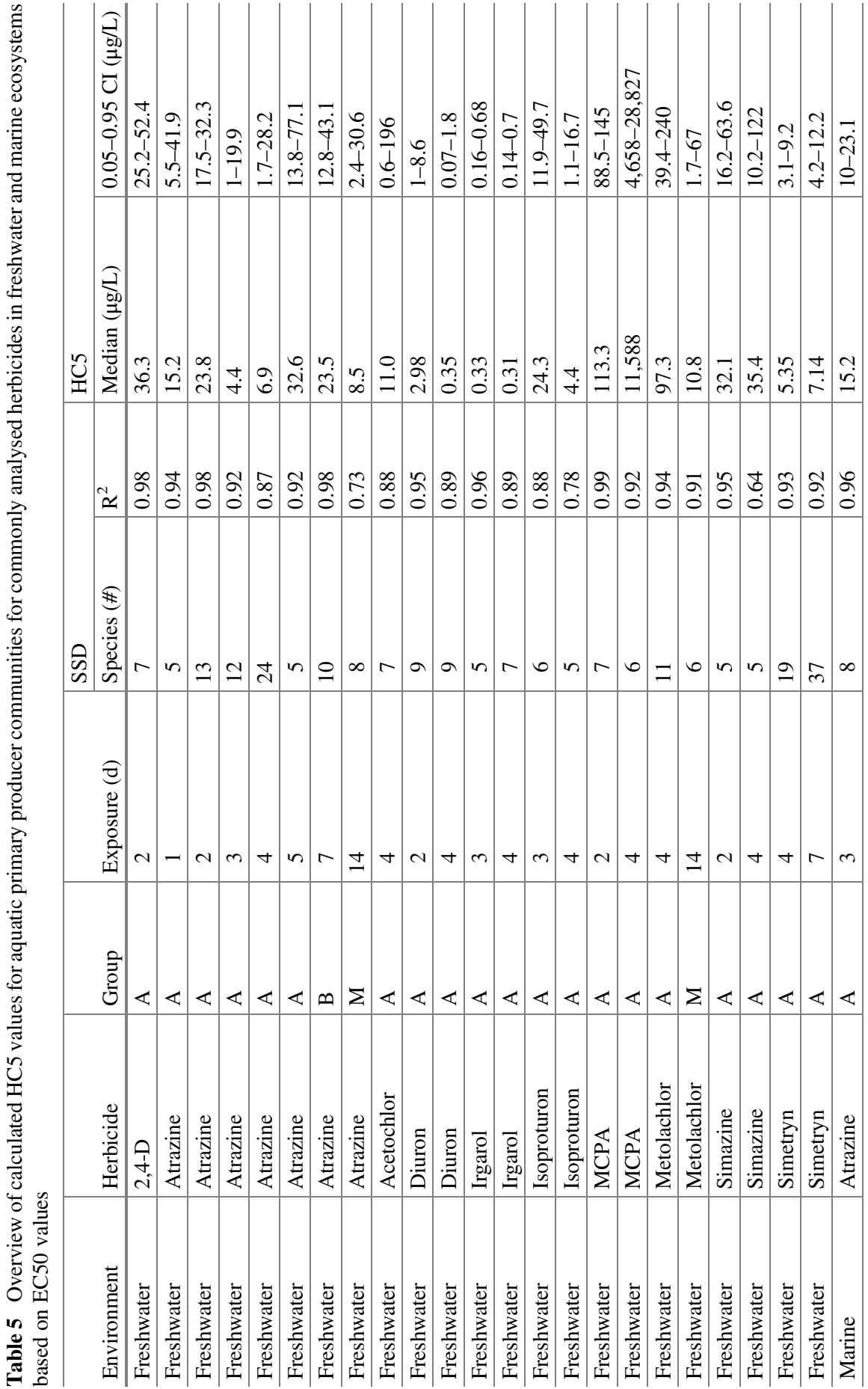




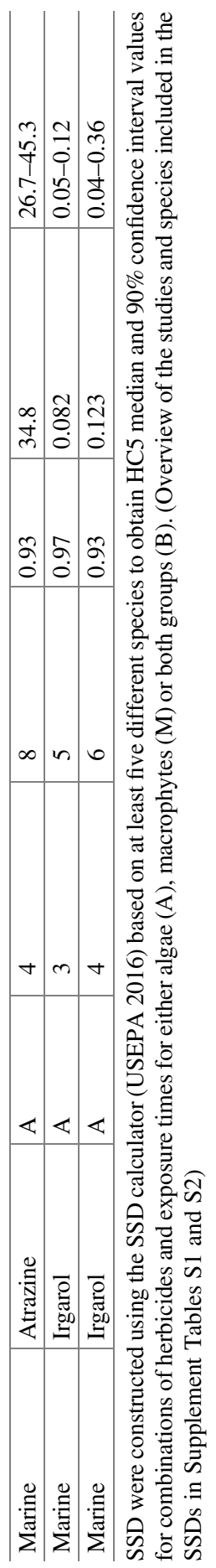




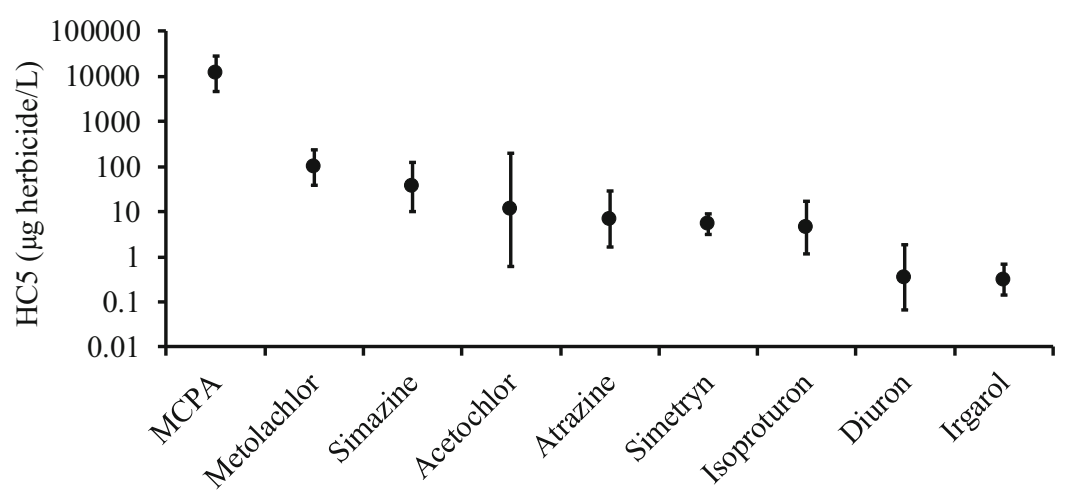

Fig. 2 Order of increasing toxicity of herbicides to freshwater algae, based on HC5 values (median $\pm 90 \% \mathrm{CI}$ ) derived from ecotoxicity tests after 4 days of exposure to the compound (Overview of the studies and species included in the SSDs in Supplement Table S1)

ecotoxicity data by means of constructing SSD curves is the only reliable way to compare herbicides and exposure times. Yet, SSDs are data hungry, requiring preferably at least EC50 values for eight different species (EFSA PPR 2013), although for the present study we went down to five data points.

Since atrazine was the most frequently studied herbicide, enough algae data were available to construct SSDs for 1, 2, 3, 4 and 5d of exposure. The median HC5 values derived from these SSD curves ranged from 4.4 to $32.6 \mu \mathrm{g} / \mathrm{L}$ (Fig. 3a), but these values were not related to the exposure time (ANOVA $\mathrm{F}_{1,4}=1.257, p=0.69$ ). Although only algal species were included in this analysis, differences in test species per exposure times could have contributed to the variation in these median HC5 values. For six other herbicides, we could calculate HC5 values based on algal species for two different exposure times. As for atrazine, no difference in HC5 values between exposure times was observed for simazine (Fig. 3f), simetryn (Fig. 3g) and irgarol (Fig. 4B). This is most likely due to the direct mode of action of these herbicides, all interfering with photosynthesis. Apparently, the herbicide concentration at the target site and the expression of the toxic effect takes already place within the shortest exposure time $(1 \mathrm{~d})$. In contrast, for herbicides that need more time to build up lethal concentrations and that are characterized by slower timeto-events EC50 values, SSD curves and HC5 values decrease with increasing exposure time (Schroer et al. 2004; Roessink et al. 2006). In the present study, this decrease in HC5 values was observed for the herbicides diuron (Fig. 3b) and isoproturon (Fig. 3c). For MCPA, a contrasting pattern in HC5 values was obtained (Fig. 3d). Finally, comparing HC5 values for different groups of aquatic primary producers showed that the sensitivity to atrazine was comparable for macrophytes after $14 \mathrm{~d}$ exposure and algae after $1 \mathrm{~d}$ to $5 \mathrm{~d}$ exposure (Fig. 3A). This is also reflected by the HC5 values obtained from both groups after $7 \mathrm{~d}$ exposure. Contrastingly, sensitivity of macrophytes to metolachlor (14d exposure) was around one order of magnitude higher compared to algae (4d exposure; Fig. 3E). 

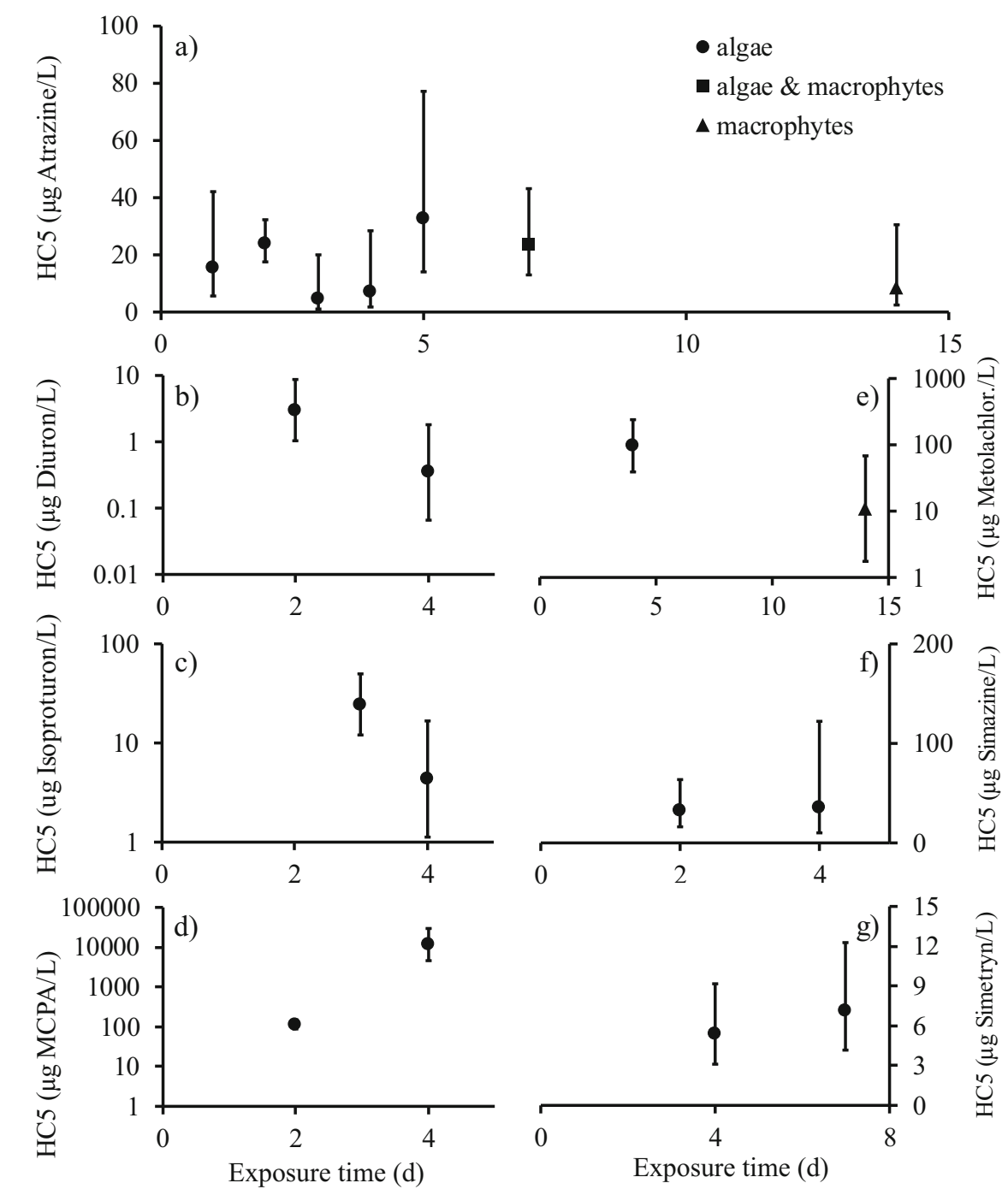

Fig. 3 Overview of HC5 values (median $\pm 90 \%$ CI) derived from SSD curves per exposure time for (a) atrazine, (b) diuron, (c) isoproturon, (d) MCPA, (e) metolachlor, (f) simazine and (g) simetryn. (Overview of the studies and species included in the SSDs in Supplement Table S1)

The wide range of effect concentrations per herbicide and the rather random distribution of the species being the most or the least sensitive one underline the urgent need to test different species, certainly more than one. The OECD and USEPA guidelines contain standard information on parameters like temperature and light conditions, but these may vary between the reported studies. The observed 
Fig. 4 Comparison HC5 values (median $\pm 90 \% \mathrm{CI}$ ) for marine and freshwater algae for (a) atrazine and (b) irgarol. (Overview of the studies and species included in the SSDs in Supplement Tables S1 and S2)

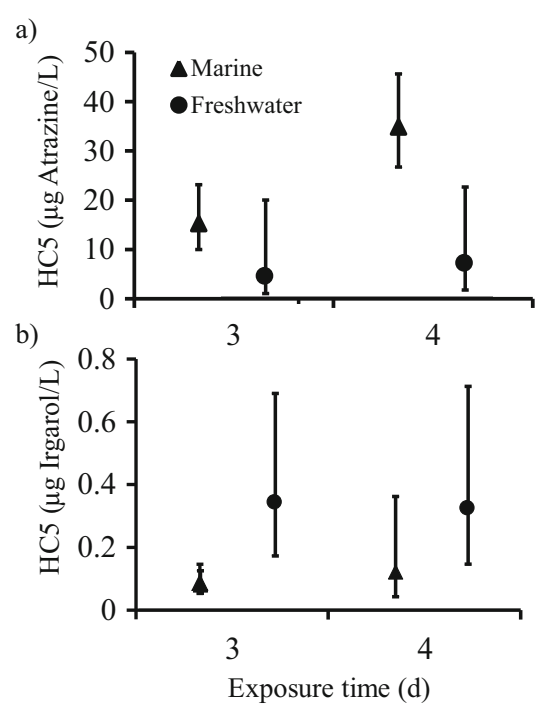

species-specific sensitivities can therefore also at least partly be attributed to the testing methods. For example, light conditions can have a strong influence on the sensitivity of aquatic primary producers, but this confounding effect differs between herbicides. The extent of the light-saturated region of photosynthesis of a species is modulated by a number of factors (e.g. availability of carbon dioxide, temperature, developmental stage, etc.), and these factors also influence the sensitivity of aquatic primary producers to herbicides (Snel et al. 1998). Comparing the sensitivity of ten aquatic macrophytes under low light intensity (irradiance $200 \mu \mathrm{mol} / \mathrm{m}^{2} / \mathrm{s}$ ) and high light intensity (irradiance $550 \mu \mathrm{mol} / \mathrm{m}^{2} / \mathrm{s}$ ), Cedergreen et al. (2004) showed that the sensitivity of the macrophytes, expressed as mean HC5 values based on EC50 values $14 \mathrm{~d}$ of repeated exposure, decreased for terbuthylazine (11 and $39 \mu \mathrm{g} / \mathrm{L}$, respectively), but increased for metsulfuron-methyl ( 0.031 and $0.014 \mu \mathrm{g} / \mathrm{L}$, respectively). In situ, this means that an individual plant in full sunlight might be nearly unaffected, while another plant of the same species in the shade might be affected to a much greater extent by a single herbicide with a photosynthesis II inhibition mode of action (Snel et al. 1998). Also, Sjollema et al. (2014) showed that the toxicity of diuron and irgarol to the marine flagellate was higher under simulated spring irradiance than under autumn irradiance, which indicates that herbicide toxicity in the field is also seasonally variable. This clearly shows that the sensitivity of aquatic primary producers to herbicides is also depending on their metabolic activity, hence the strict set of standardized test conditions used in regulatory assessment of herbicides. 


\subsubsection{Sensitivity of Marine Primary Producers to Herbicides}

For marine primary producers, 98 EC50 values for the endpoints abundance (EyC50), biomass (EbC50) and growth rate (ErC50) of mainly algae were obtained for 11 herbicides, and only a single macrophyte was tested (Supplement Table S2). Hence, far less studies have tested the effects of a lower diversity of herbicides on marine macrophytes and algae (Table 6) compared to freshwater primary producers. The only macrophyte included was Zostera marina, which was tested for only two herbicides (irgarol and diuron) (Chesworth et al. 2004), while microalgae were much more frequently represented. Consequently, only the sensitivities of algae to the most frequently detected and studied herbicides could be compared. Moreover, for several herbicides, data for only one or two marine species were available (acetochlor, bentazon, dicamba, metolachlor and terbuthylazine), leaving only five herbicides that were tested on more than one species. This strongly hampers the identification of species-specific and herbicide-specific sensitivities in the marine environment.

The inventory of the available marine ecotoxicity data revealed that the only extensively tested herbicides were 2,4-D, atrazine, diuron, irgarol and simazine (Table 6). In total 28 marine taxa belonging to 25 genera were tested, about a quarter of the numbers of freshwater taxa tested. Moreover, the marine genera were represented by fewer species than the freshwater genera. The only frequently selected test species ( $>15$ tests) were the algae Skeletonema costatum and Dunaliella tertiolecta (Supplement Table S2). Also for marine test species, the toxicity of each herbicide varied substantially (Table 6). The lowest effect concentration was observed for irgarol $(0.1 \mu \mathrm{g} / \mathrm{L})$, the same value as the lowest effect concentration observed in the freshwater tests. Similar to freshwater, the highest effect

Table 6 Overview of the sensitivity of marine primary producers to herbicides expressed as EC50 values based on measured abundance, (bio)mass or population growth (Overview of the studies and species included in the SSDs in Supplement Table S2)

\begin{tabular}{|c|c|c|c|c|c|}
\hline \multirow[b]{3}{*}{ Herbicide } & \multicolumn{5}{|c|}{ Marine algae } \\
\hline & \multirow[b]{2}{*}{ Genera (\#) } & \multirow[b]{2}{*}{ Taxa (\#) } & \multicolumn{3}{|c|}{ ExC50 (mg/L) } \\
\hline & & & $(\#)$ & median & range \\
\hline $2,4-\mathrm{D}$ & 5 & 5 & 8 & 48 & $0.68-75$ \\
\hline Acetochlor & 1 & 1 & 1 & 0.0051 & - \\
\hline Atrazine & 17 & 17 & 43 & 0.069 & $0.017-0.43$ \\
\hline Bentazon & 1 & 1 & 1 & 10.1 & - \\
\hline Dicamba & 1 & 1 & 1 & 0.49 & - \\
\hline Diuron & 11 & 11 & 15 & 0.008 & $0.0006-0.02$ \\
\hline Irgarol & 13 & 14 & 19 & 0.0004 & $0.0001-0.01$ \\
\hline Isoproturon & 2 & 2 & 2 & 0.04 & $0.027-0.053$ \\
\hline Metolachlor & 1 & 1 & 1 & 0.061 & - \\
\hline Simazine & 6 & 6 & 6 & 1.8 & $0.11-12.5$ \\
\hline Terbuthylazine & 1 & 1 & 1 & 0.031 & - \\
\hline
\end{tabular}


concentration was observed for 2,4-D (75 mg/L), but this concentration was lower than the highest effect concentration observed in the freshwater tests $(729 \mathrm{mg} / \mathrm{L})$.

Toxicity data varied most for 2,4-D and simazine, for which an around two orders of magnitude difference for both herbicides was observed. Yet, this range was substantially smaller than the six orders of magnitude difference observed for MCPA in freshwater. This is potentially due to the lack of data on marine macrophytes, causing the dataset to consist of algae only. Especially for 2,4-D, the range in effect concentrations was much smaller compared to freshwater primary producers, and the values were relatively high (EC50 range $0.68-75 \mathrm{mg} / \mathrm{L}$ ). This indicates that 2,4-D may be considered to be one of the least toxic herbicides to marine algae, because they are not sensitive to the auxin mode of action of this herbicide. Given the paucity and the wide range in marine effect concentrations, we refrained from ranking the herbicides based on their effects on marine primary producers. Moreover, considering the species-specific sensitivities for the five herbicides, also hardly any pattern was observed.

Given the limited marine ecotoxicity data, only for atrazine and irgarol, SSD curves could be constructed for 3 and $4 \mathrm{~d}$ of exposure (Table 5). Similar to freshwater, no clear relationship was observed between exposure time and the HC5 values derived from these SSD curves (Fig. 4), with no difference for irgarol and even an increase in HC5 values for atrazine. Both the 3 and 4d SSD curves showed that irgarol was at least ten times more toxic to marine algae than atrazine, following the trend observed for freshwater algae. These HC5 values also showed that irgarol was more toxic to marine species, whereas atrazine was more toxic to freshwater species. This shows that the toxicity of herbicides may differ between environmental compartments, although this statement is based on two herbicides only and is possibly biased by testing different taxonomic groups, e.g. more green algae and in freshwater and more brown and red algae in marine environments. Due to the lack of data, the ranking of the other herbicides based on their toxicity to marine primary producers can only be based on the relatively rough estimates listed in Table 5. It is concluded that toxicity data for herbicides on marine primary producers, especially macrophytes, lag behind that of freshwater species and more research is warranted.

\subsubsection{Sensitivity of Aquatic Primary Producers to Sediment-Associated Herbicides}

In comparison to exposure through surface water, there is very limited information available on the sensitivities of aquatic primary producers to exposure to herbicides via the sediment. Yet, given the accumulation of herbicides in sediments (Haynes et al. 2000; Devault et al. 2009), rooting macrophytes are expected to be exposed much more to this source of herbicides than algae or free-floating plants (LovettDoust et al. 1994). Although various rooting macrophytes have been tested, the main exposure pathway was still often via surface water (e.g. Kemp et al. 1985; Wilson and Wilson 2010; Ratte and Ratte 2014), and reported differences in sensitivity to herbicides between rooting macrophytes and other aquatic primary producers were 
consequently often based on surface water exposure. The main species currently used in standardized sediment toxicity testing is the rooting dicotyledonous Myriophyllum spp., while monocotyledonous species are mainly mentioned as suitable test species but not actually tested (Davies et al. 2003; OECD 2014b). In the USEPA ECOTOX database, there were only a few studies reporting the sensitivity of rooting macrophytes to exposure to herbicides through sediment (e.g. Burešová et al. 2013).

Given the low number of available studies, the sensitivity of aquatic primary producers to contaminated sediments is hard to compare with the sensitivity to contaminated waters. Burešová et al. (2013) reported the effects of linuron on M. spicatum in sediment-dosed test systems, with EC50 values for various endpoints ranging from 11.6 to $16.9 \mathrm{mg}$ linuron/ $\mathrm{kg}$ sediment. Since Myriophyllum can take up linuron through the roots, pore water effect concentrations provided relevant values for describing the effects on this rooting aquatic macrophyte and allowed a comparison of sediment pore water and surface water effect concentrations (Burešová et al. 2013). This comparison showed that the mean effect concentration (EC50) for plant biomass was about one order of magnitude higher in pore water in sediment-dosed systems $(1,115 \mu \mathrm{g} / \mathrm{L}$; Burešová et al. 2013) compared to the overlying water in water-dosed test systems (137 $\mu \mathrm{g} / \mathrm{L} ; \mathrm{Kemp}$ et al. 1985). Yet, taken into account the much lower root biomass (5-20\% of plant biomass for M. spicatum; Cao et al. 2012) compared to the shoot biomass (80-95\%), the total exposed plant biomass was about one order of magnitude lower in the sediment-dosed test systems.

Responses of rooting plants to herbicide exposure through the sediment are expected to be most strongly in their belowground parts, since in this case these parts of the plant are most directly exposed to the herbicide. Sensitivity of Vallisneria americana to sediment-associated contaminants could be assessed by changes in their shoot-to-root ratios, with plants grown in sediments contaminated with organic compounds having larger shoot-to-root ratios compared to plants grown in cleaner sediments (Biernacki et al. 1997). Although root endpoints were more sensitive than shoot endpoints for M. spicatum exposed to linuron via sediment, shoot biomass declined more (1.8x lower than control) compared to root biomass (1.5x lower; Burešová et al. 2013). Generally, Myriophyllum species appear to have a large variation in shoot-to-root ratios, also strongly influenced by the type of sediment used, the length of the initial cutting and the incubation time (Knauer et al. 2006, 2008). Examples for emergent rooting plants are scarce, with rice (Oryza sativa) showing a more sensitive response in the shoots compared to the roots to sediment-associated herbicides (Brinke et al. 2015).

Benthic biofilms and microalgae living on the top layer of the sediment are exposed via the overlaying water and to sediment-associated herbicides. The uptake of herbicides from the sediment by microalgae is even more direct than that by higher organisms (Diepens et al. 2014b). The uptake of herbicides from the sediment matrix is diffusion-driven and relatively fast for microalgae due to the much higher surface area-to-volume ratio compared to macrophytes. This pathway of uptake also implies that freely dissolved pore-water concentrations are the most relevant dose metric for tests with benthic microalgae (Diepens et al. 2014b). Only a few studies 
compared the herbicide sensitivity of algae living on the top layer of sediments, but some information is available for microalgae living in agricultural soils. Pipe and Cullimore (1984) showed that diuron, monuron and chloroxuron were more toxic to the soil diatom Hantzschia than chlortoluron and linuron. Atrazine application changed the species composition of the soil diatom communities in agricultural fields, with short-term ecotoxicity tests showing that the communities that had developed under herbicide stress were more tolerant to further atrazine application than the control communities (Bérard et al. 2004). Diatoms living on top of the sediment are the main aquatic primary producers in streams, but their exposure to herbicides has focused entirely on surface water contaminants (Debenest et al. 2010). Eutrophic and small diatom species were the most tolerant growth forms to atrazine, irgarol and isoproturon exposure (Debenest et al. 2010). Furthermore, diatom communities that include species capable of switching from autotrophic to heterotrophic modes when photosynthesis is inhibited (e.g. after herbicide exposure) can continue to grow, even in the presence of high concentrations of herbicides (Debenest et al. 2010).

It is concluded that the largest knowledge gap concerns the effects of sedimentassociated herbicides on primary producers. This is remarkable, since chemical pollution of water bodies in the past resulted in high concentrations of toxicants in sediments (De Deckere et al. 2011), and where regulations strongly improved chemical water quality (De Deckere et al. 2011), sediments are considered to be the largest chemical repositories on earth (Borja et al. 2004). Consequently, sediments are the most relevant environmental compartment to link adverse effects on biota to toxicants (Borja et al. 2004). Although a proposal for a risk assessment of sediment-associated herbicides is provided by the EFSA PPR (2015), an extensive catch-up must be made concerning contaminated sediment and sediment-associated herbicide toxicity to primary producers.

\subsection{Mixture Toxicity of Herbicides to Aquatic Primary Producers}

Mixture toxicity should be taken into account, since herbicides are frequently applied in mixtures and mostly occur jointly in the aquatic environment (Schreiner et al. 2016; Moser et al. 2018). Various studies have evaluated the relative contribution of different pesticide groups to risks to aquatic communities. Although insecticides (especially the highly toxic pyrethroids) generally play a large role in the direct effects of mixtures on aquatic communities, herbicides also contribute substantially. From a nationwide screening of rivers in Swiss using liquid chromatography-high-resolution mass spectrometry, Moschet et al. (2014) calculated that herbicide mixtures made up $60-80 \%$ of the total risk of pesticides together in the rivers. However, the pyrethroids were not included in the analysis, while fungicides were not considered in the risk assessment based on three organism 
groups (plants, vertebrates and invertebrates). Mixture effects of herbicides and fungicides on aquatic primary producers should also be taken into account, since fungicides may affect algae as well (Guida et al. 2008) and their risk to aquatic primary producers may be underestimated (Reilly et al. 2012).

For herbicides with the same mode of action, concentration addition has been observed for algal community responses (Arrhenius et al. 2004). Hence, the only difference between the herbicides in the mixture is the relative potency of the compounds, and a mixture of herbicides with the same mode of action thus poses a concentration additive effect on primary producers (Backhaus et al. 2004). Deviations from concentration addition can be seen as a first indication of the herbicides in the mixture having a different mode of action. Herbicides with the same mode of action often act on a set of biological pathways related to a specific metabolic process, e.g. photosynthesis. Still there are many pathways involved in most metabolic processes, so herbicides with a specific mode of action (e.g. photosynthesis inhibition) can act on different molecular targets. Different photosynthesis-inhibiting herbicides can thus still have different mechanisms of action (Busch et al. 2016). For photosynthesis-inhibiting herbicides, this mechanism is often known, but for many other types of herbicides, it is often difficult to assess the exact mechanism of action in different groups of aquatic primary producers (Vonk et al. 2009).

The effects of herbicide mixtures on aquatic primary producers show variation, depending on the used herbicide combinations, test species and endpoints assessed. We have separated here studies using growth or biomass as endpoint and studies using various endpoints related to photosynthetic activity. Faust et al. (1993) tested 29 binary mixtures of 9 different herbicides on the unicellular green algae Chlorella fusca over $24 \mathrm{~h}$ development, and for $85 \%$ of the mixtures, results were consistent with concentration additivity. This was also observed for growth inhibition in Pseudokirchneriella subcapitata following exposure to mixtures of diuron and hexazinone, while the independent action model underestimated the combined effect (Hasenbein et al. 2017). Contrary, the independent action model fitted best the effects of a mixture of atrazine and sulfentrazone on the same microalgae (P. subcapitata) and on the floating macrophyte Lemna minor (Thorngren et al. 2017), indicating different mechanisms of action for these herbicides.

Results from studies assessing mixture toxicity of herbicides to aquatic primary producers using photosynthesis endpoints are also providing variable results. Whether additive responses, synergism or antagonism occurred depended on the mode of action of herbicides and the relative concentrations of the herbicides in the mixture. Binary mixtures of herbicides (diuron, tebuthiuron, atrazine, simazine and hexazinone) exhibited additive toxicity to the microalgae Navicula sp., Cylindrotheca closterium, Nephroselmis pyriformis and Phaeodactylum tricornutum (Magnusson et al. 2010). Sjollema et al. (2014) tested the effect of an equitoxic mixture of the herbicides irgarol and diuron on photosynthesis of Dunaliella tertiolecta. Although the mode of action of both herbicides was inhibition of photosynthesis, a more than additive effect of the herbicides in the mixture was observed. Photosynthetic activity of the marine cyanobacterium Arthrospira maxima showed both additive and antagonistic effects when exposed to the herbicides diuron 
and irgarol, depending on the relative concentrations of the herbicides in the mixture (Kottuparambil et al. 2013). Also for the floating macrophyte Lemna sp., binary herbicide mixtures (atrazine, diuron, simazine and hexazinone) resulted in both additive and antagonistic effects on photosynthesis (Kumar and Han 2011). Using a herbicide mixture of atrazine, diuron and isoproturon, Knauert et al. (2010) observed concentration additive effects on photosynthetic efficiency in Myriophyllum spicatum exposed to equitoxic herbicide concentrations.

Besides herbicide mixtures, also a wide variety of other pesticides can be present in the aquatic environment (e.g. Ensminger et al. 2013). These pesticide mixtures can exhibit toxic effects on aquatic primary producers. Faure et al. (2012) showed synergistic phytotoxic effects of a mixture of organochlorines (lindane $(\mathrm{HCH})$, monochlorobenzene (MCB), 1,4-dichlorobenzene (DCB) and 1,2,4trichlorobenzene (TCB)) on the aquatic emergent macrophyte Phragmites australis. Applied herbicides are often products with two or three different active ingredients with information available on their mixture toxicity from regulatory testing. However, in aquatic ecosystems, different events of herbicides application can easily result in different combinations of active herbicides and potential mixture effects on aquatic primary producers.

\section{Retrospective Site-Specific Risks Assessment of Herbicides for Aquatic Primary Producers}

The application of pesticides always involves exposure of non-target organisms, which can be reduced by increasing the specificity of the pesticides. In the case of herbicides, animals can be spared at least to some extent if the herbicides have a plant-specific mode of action, like most of the categories listed in Table 2, with photosynthesis inhibition being the most obvious one (Van den Brink et al. 2006). Yet, non-target primary producers remain equally affected as the target ones, causing aquatic primary producers to be permanently at risk of herbicide exposure. In a retrospective site-specific risk assessment, these risks may be substantiated by comparing and weighing effect concentrations and measured environmental concentrations. A refinement of this method can be applied if for a specific herbicide enough ecotoxicity data are available to construct SSD curves. In this case, one can derive the fraction of species probably affected at a measured ambient concentration ( $\mathrm{X}$ to $\mathrm{Y}$ in the SSD).

The major drawback of the abovementioned methodologies is that they are based on single herbicides. Yet, in heavily anthropogenically exploited areas, risks to aquatic primary producers are generally caused by mixtures of a myriad of (un)known compounds, with estimates of up thousands of compounds being present in large European rivers (Loos et al. 2009; Altenburger et al. 2015; Storck et al. 2015). Thus, a large portion of toxic risks in surface waters cannot be attributed to compounds measured by water authorities. To meet these challenges, the SSD 
approach can be further refined by deriving a multi-substance potentially affected fraction of species (msPAF). The msPAF model is designed to assess the risk of mixtures of toxicants using the SSD principles (Traas et al. 2002; de Zwart and Posthuma 2005). This model applies first concentration addition to calculate a single risk value for substances that have a shared toxic mode of action and then applies response addition to sum the toxicity risks of each mode of action. The resulting msPAF value describes the potentially affected fraction of species from exposure to a complex mixture (Traas et al. 2002; de Zwart and Posthuma 2005). This approach has been successfully applied to assess the risk of a mixture of pesticides, including many herbicides, in different regions (e.g. Wilson and Wilson 2011; Rämö et al. 2018).

Alternatively, understanding of the risks of herbicide exposure for aquatic primary producers can also be achieved by a shift towards new monitoring methods that do not depend on chemical analysis of priority substances solely, but consider the biological effects of the entire micro-pollutant mixture first. Therefore, there is a need for effect-based monitoring strategies that employ bioassays to identify environmental risk (e.g. De Baat et al. 2018). Responses in bioassays are caused by all bioavailable (un)known compounds and their metabolites, whether or not they are listed as priority substances. All toxicity tests described in $\$ 3.2$ can be employed as bioassays, in which the responses of the primary producers to contaminated water and sediments samples can be determined, providing a direct indication of the potential ecological risks. Likewise, all the different endpoints described in $\$ 3.3$ can be assessed in such bioassays, including survival, growth, reproduction, photosynthesis, etc. Applying bioassays enables an efficient and effective assessment of the toxicity of environmental samples to primary producers because it (1) identifies the presence of herbicides that would be overlooked by routine chemical WFD monitoring and (2) avoids redundant chemical analyses by focusing only on (non-) target screening in samples with demonstrated effects (De Baat et al. 2018). Major drawbacks in applying bioassays are the difficulties in relating the observed effects to specific compounds and the effects of confounding factors, like a poor nutritional value of the field samples, causing false positives.

\subsection{Risk Assessment of Aqueous Herbicides for Aquatic Primary Producers}

Monitoring efforts may vary widely between countries, the Netherlands being one of the few countries for which an open online platform on pesticide monitoring is publicly available (Vijver et al. 2008). Consulting this atlas revealed that for atrazine, diuron, isoproturon, MCPA, metolachlor and simazine, the measured environmental concentrations are all in the low $\mathrm{ng} / \mathrm{L}$ range, hence generally at least three orders of magnitude lower than the HC5 values listed in Table 5 that generally fall in the $\mu \mathrm{g} / \mathrm{L}$ range. This suggests that in the Netherlands, there is no actual risk of waterborne 
herbicides to aquatic primary producers. However, a number of considerations should be taken into account, mixture toxicity being the most obvious one. Yet, if effect concentrations and field concentrations differ a factor thousand, then only mixtures consisting of thousands of compounds may in the end come close to the effect concentrations. This may only be the case in the most downstream part of large rivers, but their concentrations are also generally further diluted. Ten to 20 years ago, herbicide concentrations were substantially higher, about a factor of 10 (www. bestrijdingsmiddelenatlas.nl; Vijver et al. 2008), but even then the difference between environmental concentrations and effect concentrations was still a factor hundred. Also, peak discharges may be missed by routine grab sampling monitoring, but this strongly depends on the monitoring frequency and intensity. Alternatively, passive sampling may be employed, strongly diminishing the chance of missing these peaks, but on the other hand, the final time integrated concentrations in the passive samplers also dampen these peaks. Munz et al. (2017) screened 24 Swiss WWTPs for almost 400 chemically synthesized pesticides and pharmaceuticals. Detected herbicide concentrations were several orders of magnitude lower than the HC5 values derived in the present review, confirming the low risk of herbicides to aquatic primary producers.

Fang et al. (2019) reported the minimum, median and maximum concentrations of a wide range of pesticides in Europe, China and the USA. For acetochlor, irgarol, isoproturon, MCPA, metolachlor and simazine, even the maximum concentrations were still at least a factor of 10 below the HC5 values. In contrast, for atrazine the maximum concentrations measured in China and the USA were very similar to the HC5 values listed in Table 5, suggesting an actual risk to aquatic primary producers. For diuron, the HC5 values varied, but nevertheless the maximum concentrations measured in the USA $(1.36 \mu \mathrm{g} / \mathrm{L})$ were half of the median $2 \mathrm{~d} \mathrm{HC} 5$ value $(2.98 \mu \mathrm{g} / \mathrm{L})$ and even around four times higher than the median $4 \mathrm{~d}$ HC5 values $(0.35 \mu \mathrm{g} / \mathrm{L})$, indicating serious risks. Exceptional high risks would be anticipated based on the diuron concentrations measured by Hermosin et al. (2013) in Spain. The median $(0.6 \mu \mathrm{g} / \mathrm{L})$ and mean concentration $(2.36 \mu \mathrm{g} / \mathrm{L})$ that they reported are very similar to the HC5 ranges (overall $0.07-8.6 \mu \mathrm{g} / \mathrm{L}$ ) calculated in the present review. Moreover, the maximum concentration that Hermosin et al. (2013) measured $(21 \mu \mathrm{g} / \mathrm{L})$ is even ten- to a hundred-fold higher than the median HC5 values for diuron. The latter would imply that approximately $60 \%$ of the EC50 values plotted in the SSD would be exceeded. Moreover, in such cases, mixture toxicity would likely play a role as well. An appropriate risk assessment of the generally occurring mixtures of compounds is, however, hampered by the compound approach involved in using SSDs. A reliable estimation of the actual risks at contaminated sites can therefore only be obtained by employing bioassays that respond to the entire mixture of bioavailable (un)known herbicides present in the environmental samples.

De Baat et al. (2018) employed an algal photosynthesis bioassay on a nationwide scale in the Netherlands to identify surface water toxicity to algae and subsequently to identify the causing compound(s). Out of 39 surface water locations, toxicity was observed at only one location. Chemical screening for 151 commonly applied pesticides identified 3 suspect herbicides (linuron, dimethenamid and the metabolite 
desethylterbuthylazine) that were present in the water sample above their respective quality standards. Generating EC50 values revealed that linuron was solely responsible for the observed effects at this location. Neale et al. (2017) applied chemical analysis and bioanalysis to assess the micro-pollutant burden during low flow conditions upstream and downstream of three wastewater treatment plants (WWTPs) discharging into small streams in the Swiss Plateau. They could explain that the observed effects on the photosystem II inhibition bioassays by ten detected herbicides, with main contributions by diuron and terbuthylazine). This was in contrast to the observed effects for most other bioassays, including activation of the aryl hydrocarbon receptor, activation of the androgen receptor, activation of the oestrogen receptor and acetylcholinesterase inhibition.

The success of surface water screenings relies largely on the endpoint specificity and scale of the selected bioassays, with in vitro or small-scale in vivo bioassays with specific drivers of adverse effects allowing for focused identification of toxicity and subsequent confirmation of the toxic compounds (Leusch et al. 2014; Brack et al. 2016). Microalgal photosynthesis is a sensitive and well-studied bioassay endpoint to identify hazardous effects of herbicides in surface waters (e.g. Ralph et al. 2007; Sjollema et al. 2014; Booij et al. 2015). Adequate selection of bioassays employed in water quality monitoring can thus greatly aid in narrowing down the identification of compound(s) that cause environmental risks (De Baat et al. 2018). The bioassays targeting photosynthesis inhibition by herbicides are often successful due to the specific mode of action and the sensitivity of PSII inhibition as an endpoint (Neale et al. 2017). Yet, herbicides with a different mode of action, like commonly observed auxin stimulating herbicides (e.g. Ensminger et al. 2013), are not detected using such microalgae bioassays.

\subsection{Risk Assessment of Sediment-Associated Herbicides for Aquatic Primary Producers}

While knowledge regarding the analysis and improvement of water quality is increasing, knowledge considering sediments and sediment-water-plant interactions specifically remains relatively scarce. Hence, more insight into the impact of changes induced by human activities on sediment and sediment-inhabiting organisms is required, since sediments are the largest chemical repositories on earth (Borja et al. 2004; Babut et al. 2005). Moreover, sediments nowadays act as a source of pollutants rather than as a sink, releasing a variety of stored toxicants and other detrimental components (Brils 2002; Förstner 2004; Chon et al. 2012). Despite the importance of contaminated sediments considering water quality assessment and risks for aquatic (primary producer) communities, the European Water Framework Directive (WFD) has focused primarily on compounds in the water column, mentioning water 373 times and sediment only 7 times (Borja et al. 2004). Moreover, the risks of herbicides accumulated in the sediments are strongly linked to the presence 
of other hazardous compounds, since in agricultural and urban areas, rooting primary producers are often influenced by mixtures of herbicides, heavy metals and many other unmonitored compounds in the sediment (Kronvang et al. 2003).

Microalgae generally have a short life-span and reproduction occurs often through simple cell division. Exposing microalgae for a couple of days to a few weeks, timeframes possible within the available ecotoxicity tests, will therefore also include reproduction of the species. Also for Lemna species, one can argue that the whole life-cycle is covered by the available toxicity test. However, assessing the risk for larger macrophytes is complicated, particularly when taking into account the seasonal growing and decay phase (Hill et al. 1994). Given the longer life-span of most (rooting) macrophytes (few months to even years; Cronk and Fennesy 2001), no standardized ecotoxicity test includes the entire life-cycle of these vascular plants. Hence, there is limited information available on the effects of herbicides on germination, flowering, seed formation and resource allocation during senescence of macrophytes (but see Moore et al. 1999, Gao et al. 2011; Moore and Locke 2012). Especially in the early life stages (seed germination) and during senescence and reallocation of resources to belowground parts, aquatic plants could be sensitive to sediment-associated herbicides. Mesocosm studies can be used to determine longterm effects of pesticides on aquatic primary producers, since both direct and indirect effects are taken into account in these studies (Müller et al. 2019). Still, mostly endpoints related to species composition and plant biomass are reported with less information on endpoints related to flowering, seed production and belowground storage of resources.

In the marine environment, suspicions regarding the risks of contaminated sediments are hard to confirm, since there are no standardized ecotoxicity tests using marine rooting macrophytes available. Assays for marine macrophytes (e.g. using leaves of the seagrass Halophila ovalis; Wilkinson et al. 2015) are currently being developed, but these still often focus on exposure through surface water only. Hence, it cannot be determined whether marine primary producers are affected by sedimentbound herbicides. Located in the coastal zones and influenced by rivers, seagrass meadows are contaminated by herbicides transported through the catchment to the sea (e.g. Scarlett et al. 1999; Haynes et al. 2000). For example, the modelled discharge of six widely used herbicides (atrazine, tebuthiuron, simazine, ametryn, diuron and hexazinone) to the Great Barrier Reef was on average 17,000 kg per year with the main risks for this area (Brodie et al. 2013, 2017). Although detected concentrations of herbicides in sediments of the Great Barrier Reef were relatively low (below $1 \mu \mathrm{g} / \mathrm{kg}$ sediment; Haynes et al. 2000), risk assessment of pesticides in sediments is restricted because the Australian sediment quality guidelines are limited in their scope to evaluate pesticide bioavailability (Brodie and Landos 2019). Seagrasses are exposed to herbicides and their degradation products through both the surface water (leaves) and the sediment (roots). Although a few studies have reported the impact of herbicides on seagrasses (see Devault and Pascaline (2013) for an overview), most studies reported impact on plant physiological endpoints (photosynthesis) only and not on overall growth. Seagrass vulnerability to short exposures of high concentrations of herbicides has been observed (Macinnis-Ng and 
Ralph 2004), and the combined effects of high temperatures and the herbicide atrazine were more harmful to seagrass compared to a single pressure (Gao et al. 2017). However, the risk of herbicides through long-term exposure to mixtures of compounds generally present in the sediment of contaminated coastal areas remains unknown. Adjustments of environmental quality standards may therefore be needed in order to increase the protection level of marine species to herbicides. Priority should be given to evaluate if marine primary producers are currently sufficiently protected against the risks of exposure to hazardous concentrations of herbicides.

Comparable to surface water screenings, a reliable estimation of the actual risks at contaminated sediment sites can only be obtained by employing bioassays that respond to the entire mixture of bioavailable (un)known compounds present in the sediment and the interstitial water. Magnusson et al. (2013) compared the phytotoxicity of interstitial water extracts from sediments on benthic microalgae to the expected phytotoxicity of compounds detected in the overlying water. The herbicide concentrations in the interstitial water explained most of the phytotoxicity measured in the bioassay, and this photoinhibition was even higher than expected, indicating the presence of unidentified phytotoxins in the sediment pore water. Rooting macrophyte species have also been used in bioassays to assess sediment quality. In estuaries, Lewis et al. (2001) observed significant stimulatory and inhibitory effects on early seedling growth of Scirpus robustus (saltmarsh bulrush) and Spartina alterniflora (saltmarsh cordgrass), relative to a reference sediment. However, only in 3 of the 15 tests, these effects were related to pesticides (Lewis et al. 2001). Feiler et al. (2004) showed that growth of the freshwater macrophyte Myriophyllum aquaticum was depending on the origin of the sediment tested, with contamination in the sediments causing adverse effects on the plants. Successful application of bioassays to assess the toxicity of sediment-associated herbicides and to identify compounds of concern relates to (1) the identification of sensitive plant species and suitable response parameters; (2) the determination of the influence of sediment chemical and physical characteristics on plant growth; and (3) the quantification of the (bio)available concentrations of herbicides and other phytotoxins in the sediment-pore water matrix.

\section{Conclusions}

The aim of the present review was to give an overview of the current state of science concerning herbicide exposure and toxicity to aquatic primary producers. Assessing the open literature revealed that the unintentional as well as intentional sources of herbicides in the aquatic environment are numerous, evidently leading to the widespread presence of herbicides, inevitably leading to the exposure of non-target primary producers. The fate of herbicides in the environment is determined by the combination of the chemical properties and the formulation of the herbicides, the local environmental conditions and the timing, rate and method of application. 
Overall, this results in exposure concentrations showing strong temporal and spatial variations and consisting of mixtures of herbicides.

Among the available toxicity tests with aquatic primary producers, there are a bias towards algae compared to macrophytes and a bias to water compared to sediment exposure. In response to ignoring the sediment as environmental compartment of concern, the OECD guideline for the macrophyte Myriophyllum has been extended with rooting plants allowing to test the toxicity of sediment-associated herbicides, while a test with the rooted emergent macrophyte Glyceria is currently being developed. Based on the outcome of the available ecotoxicity tests, it was concluded that the most sensitive as well as the least sensitive species differed per herbicide and that the observed effect concentrations for herbicides were rather similar independent from the exposure time. To come to a reliable hazard assessment for the effects of herbicides on primary producers, extensive ecotoxicity testing is required, especially considering macrophytes and marine herbicide toxicity. Yet, it is concluded that the largest knowledge gap concerns the effects of sediment-associated herbicides on primary producers.

Comparing environmental concentrations and effect concentrations demonstrated that generally there is no actual risk of waterborne herbicides to aquatic primary producers. Still, median concentrations of atrazine and especially of diuron measured in China, the USA and Europe represented moderate risks for primary producers. Maximum concentrations due to misuse and accidents may even cause the exceedance of almost $60 \%$ of the effect concentrations plotted in SSDs. Applying bioassays to detect the impact of unknown herbicide mixtures and to identify the herbicide of concern is a successful approach, especially for the photosynthesisinhibiting herbicides. However, for herbicides with other modes of action, the use of bioassays remains challenging. It is concluded that to come to a reliable herbicide hazard and risk assessment, an extensive catch-up must be made concerning macrophytes, the marine environment and especially sediment as overlooked and understudied environmental compartment.

\section{Summary}

The aim of the present review was to give an overview of the current state of science concerning herbicide exposure and toxicity to primary producers. To this end we assessed the open literature, revealing the widespread presence of (mixtures of) herbicides, inevitably leading to the exposure of non-target primary producers. Yet, herbicide concentrations show strong temporal and spatial variations. Concerning herbicide toxicity, it was concluded that the most sensitive as well as the least sensitive species differed per herbicide and that the observed effect concentrations for some herbicides were rather independent from the exposure time. More extensive ecotoxicity testing is required, especially considering macrophytes and marine herbicide toxicity. Hence, it was concluded that the largest knowledge gap concerns the effects of sediment-associated herbicides on primary producers in 
the marine/estuarine environment. Generally, there is no actual risk of waterborne herbicides to aquatic primary producers. Still, median concentrations of atrazine and especially of diuron measured in China, the USA and Europe represented moderate risks for primary producers. Maximum concentrations due to misuse and accidents may even cause the exceedance of almost $60 \%$ of the effect concentrations plotted in SSDs. Using bioassays to determine the effect of contaminated water and sediment and to identify the herbicides of concern is a promising addition to chemical analysis, especially for the photosynthesis-inhibiting herbicides using photosynthesis as endpoint in the bioassays. This review concluded that to come to a reliable herbicide hazard and risk assessment, an extensive catch-up must be made concerning macrophytes, the marine environment and especially sediment as overlooked and understudied environmental compartments.

Acknowledgements We thank Loesjka van der Waal for an initial screening of herbicide literature, Milo de Baat for advice on the species sensitivity distribution calculations and the constructive comments of three reviewers on the manuscript.

Conflict of Interest Statement On behalf of all authors, the corresponding author states that there is no conflict of interest.

\section{References}

Altenburger R, Ait-Aissa S, Antczak P et al (2015) Future water quality monitoring - adapting tools to deal with mixtures of pollutants in water resource management. Sci Total Environ 512-513:540-551. https://doi.org/10.1016/j.scitotenv.2014.12.057

Anudechakul C, Vangnai AS, Ariyakanon N (2015) Removal of chlorpyrifos by water hyacinth (Eichhornia crassipes) and the role of a plant-associated bacterium. Int $\mathrm{J}$ Phytoremediation 17:678-685. https://doi.org/10.1080/15226514.2014.964838

Arrhenius Å, Grönvall F, Scholze M et al (2004) Predictability of the mixture toxicity of 12 similarly acting congeneric inhibitors of photosystem II in marine periphyton and epipsammon communities. Aquat Toxicol 68:351-367. https://doi.org/10.1016/j.aquatox.2004.04.002

Arts GH, Belgers JDM, Hoekzema CH, Thissen JT (2008) Sensitivity of submersed freshwater macrophytes and endpoints in laboratory toxicity tests. Environ Pollut 153:199-206. https://doi. org/10.1016/j.envpol.2007.07.019

Ashauer R, Escher BI (2010) Advantages of toxicokinetic and toxicodynamic modelling in aquatic ecotoxicology and risk assessment. J Environ Monit 12:2056-2061. https://doi.org/10.1039/ C0EM00234H

ASTM (American Society for Testing and Materials) (2012a) Standard guide for conducting renewal phytotoxicity tests with freshwater emergent macrophytes. ASTM international E1841-04

ASTM (American Society for Testing and Materials) (2012b) Standard guide for conducting sexual reproduction tests with seaweeds. ASTM international E1498-92

ASTM (American Society for Testing and Materials) (2012c) Standard guide for conducting static toxicity tests with Lemna gibba G3. ASTM international E1415-91

ASTM (American Society for Testing and Materials) (2012d) Standard guide for conducting static toxicity tests with microalgae. ASTM international E1218-04 
ASTM (American Society for Testing and Materials) (2012e) Standard practice for algal growth potential testing with Pseudokirchneriella subcapitata. ASTM international D3978-04

Babut MP, Ahlf W, Batley GE et al (2005) International overview of sediment quality guidelines and their uses. In: Wenning RJ, Batley GE, Ingersoll CJ, Moore DW (eds) Use of sediment quality guidelines and related tools for the assessment of contaminated sediments. Society of Environmental Toxicity and Chemistry, Pensacola, pp 345-382

Backhaus T, Faust M, Scholze M et al (2004) Joint algal toxicity of phenylurea herbicides is equally predictable by concentration addition and independent action. Environ Toxicol Chem 23:258-264. https://doi.org/10.1897/02-497

Bakker ES, Wood KA, Pagès JF et al (2016) Herbivory on freshwater and marine macrophytes: A review and perspective. Aquat Bot 135:18-36. https://doi.org/10.1016/j.aquabot.2016.04.008

Barko JW, Gunnison D, Carpenter SR (1991) Sediment interactions with submersed macrophyte growth and community dynamics. Aquat Bot 41:41-65. https://doi.org/10.1016/0304-3770(91) 90038-7

Baudrot V, Charles S (2019) Recommendations to address uncertainties in environmental risk assessment using toxicokinetic-toxicodynamic models. Sci Rep 9:11432. https://doi.org/10. 1038/s41598-019-47698-0

Belgers JDM, Aalderink GH, Arts GHP, Brock TCM (2011) Can time-weighted average concentrations be used to assess the risks of metsulfuron-methyl to Myriophyllum spicatum under different time-variable exposure regimes? Chemosphere 85:1017-1025. https://doi.org/10. 1016/j.chemosphere.2011.07.025

Bérard A, Rimet F, Capowiez Y et al (2004) Procedures for determining the pesticide sensitivity of indigenous soil algae: a possible bioindicator of soil contamination? Arch Environ Contam Toxicol 46:24-31. https://doi.org/10.1007/s00244-003-2147-1

Bergtold M, Dohmen GP (2011) Biomass or growth rate endpoint for algae and aquatic plants: relevance for the aquatic risk assessment of herbicides. Integr Environ Assess Manage 7:237-247. https://doi.org/10.1002/ieam.136

Biernacki M, Lovett-Doust J, Lovett-Doust L (1997) Laboratory assay of sediment phytotoxicity using the macrophyte Vallisneria americana. Environ Toxicol Chem 16:472-478. https://doi. org/10.1002/etc.5620160312

Birk S, Bonne W, Borja A et al (2012) Three hundred ways to assess Europe's surface waters: an almost complete overview of biological methods to implement the water framework directive. Ecol Indic 18:31-41. https://doi.org/10.1016/j.ecolind.2011.10.009

Booij P, Sjollema SB, Van der Geest HG et al (2015) Toxic pressure of herbicides on microalgae in Dutch estuarine and coastal waters. J Sea Res 102:48-56. https://doi.org/10.1016/j.seares.2015. 05.001

Borja A, Valencia V, Franco J et al (2004) The water framework directive: water alone, or in association with sediment and biota, in determining quality standards? Mar Pollut Bull 49:8-11. https://doi.org/10.1016/j.marpolbul.2004.04.008

Boros G, Søndergaard M, Takács P, Vári A, Tátrai I (2011) Influence of submerged macrophytes, temperature, and nutrient loading on the development of redox potential around the sedimentwater interface in lakes. Hydrobiologia 665:117-127. https://doi.org/10.1007/s10750-0110609-4

Boxall ABA, Sinclair CJ, Fenner K et al (2004) When synthetic chemicals degrade in the environment. Environ Sci Technol 38:368A-375A. https://doi.org/10.1021/es040624v

Brack W, Ait-Aissa S, Burgess RM et al (2016) Effect-directed analysis supporting monitoring of aquatic environments - an in-depth overview. Sci Total Environ 544:1073-1118. https://doi. org/10.1016/j.scitotenv.2015.11.102

Brain RA, Johnson DJ, Richards SM et al (2004) Microcosm evaluation of the effects of an eight pharmaceutical mixture to the aquatic macrophytes Lemna gibba and Myriophyllum sibiricum. Aquat Toxicol 70:23-40. https://doi.org/10.1016/j.aquatox.2004.06.011 
Briggs GG, Bromilow RH, Evans AA (1982) Relationship between lipophilicity and root uptake and translocation of non-ionised chemicals by barley. Pestic Sci 13:495-504. https://doi.org/10. $1002 /$ ps. 2780130506

Brils J (2002) The SedNet mission. J Soils Sed 2:2-3. https://doi.org/10.1007/BF02991243

Brinke A, Buchinger S, Reifferscheid G, Klein R, Feiler U (2015) Development of a sediment contact test with rice for the assessment of sediment-bound pollutants. Environ Sci Pollut Res 22:12664-12675. https://doi.org/10.1007/s11356-015-4452-4

Brodie J, Landos M (2019) Pesticides in Queensland and great barrier reef waterways - potential impacts on aquatic ecosystems and the failure of national management. Estuar Coast Shelf Sci 230:106447. https://doi.org/10.1016/j.ecss.2019.106447

Brodie JE, Waterhouse J, Schaffelke B et al (2013) Reef water quality scientific consensus statement 2013. Queensland Government, Department of the Premier and Cabinet, Brisbane

Brodie JE, Lewis SE, Collier CJ et al (2017) Setting ecologically relevant targets for river pollutant loads to meet marine water quality requirements for the great barrier reef, Australia: a preliminary methodology and analysis. Ocean Coast Manage 143:136-147. https://doi.org/10.1016/j. ocecoaman.2016.09.028

Burešová H, Crum SJH, Belgers JDM et al (2013) Effects of linuron on a rooted aquatic macrophyte in sediment-dosed test systems. Environ Pollut 175:117-124. https://doi.org/10.1016/j.envpol. 2012.12.030

Busch W, Schmidt S, Kühne R et al (2016) Micropollutants in European rivers: a mode of action survey to support the development of effect-based tools for water monitoring. Environ Toxicol Chem 35:1887-1899. https://doi.org/10.1002/etc.3460

Campos MMC, Faria VHF, Teodoro TS et al (2013) Evaluation of the capacity of the cyanobacterium Microcystis novacekii to remove atrazine from a culture medium. J Environ Sci Health Part B 48:101-107. https://doi.org/10.1080/03601234.2013.726891

Cao JJ, Wang Y, Zhu ZL (2012) Growth response of the submerged macrophyte Myriophyllum spicatum to sediment nutrient levels and water-level fluctuations. Aquat Biol 17:295-303. https://doi.org/10.3354/ab00484

Casado J, Brigden K, Santillo D, Johnston P (2019) Screening of pesticides and veterinary drugs in small streams in the European Union by liquid chromatography high resolution mass spectrometry. Sci Total Environ 670:1204-1225. https://doi.org/10.1016/j.scitotenv.2019.03.207

Cedergreen N, Spliid NH, Streibig JC (2004) Species-specific sensitivity of aquatic macrophytes towards two herbicide. Ecotoxicol Environ Saf 58:314-323. https://doi.org/10.1016/j.ecoenv. 2004.04.002

Cedergreen N, Andersen L, Olesen CF et al (2005) Does the effect of herbicide pulse exposure on aquatic plants depend on $\mathrm{K}_{\mathrm{ow}}$ or mode of action? Aquat Toxicol 71:261-271. https://doi.org/10. 1016/j.aquatox.2004.11.010

Chalifour A, LeBlanc A, Sleno L et al (2016) Sensitivity of Scenedesmus obliquus and Microcystis aeruginosa to atrazine: effects of acclimation and mixed cultures, and their removal ability. Ecotoxicology 25:1822-1831. https://doi.org/10.1007/s10646-016-1728-5

Chefetz B, Bilkis YI, Polubesova T (2004) Sorption-desorption behavior of triazine and phenylurea herbicides in Kishon river sediments. Water Res 38:4383-4394. https://doi.org/10.1016/j. watres.2004.08.023

Chesworth JC, Donkin ME, Brown MT (2004) The interactive effects of the antifouling herbicides Irgarol 1051 and Diuron on the seagrass Zostera marina (L.). Aquat Toxicol 66:293-305. https://doi.org/10.1016/j.aquatox.2003.10.002

Chon HS, Ohandja DG, Voulvoulis N (2012) The role of sediments as a source of metals in river catchments. Chemosphere 88:1250-1256. https://doi.org/10.1016/j.chemosphere.2012.03.104

Clausen L, Larsen F, Albrechtsen HJ (2004) Sorption of the herbicide dichlobenil and the metabolite 2,6-dichlorobenzamide on soils and aquifer sediments. Environ Sci Technol 38:4510-4518. https://doi.org/10.1021/es035263i 
Coors A, Kuckelkorn J, Hammers-Wirtz M, Strauss T (2006) Application of in-situ bioassays with macrophytes in aquatic mesocosm studies. Ecotoxicology 15:583-591. https://doi.org/10.1007/ s10646-006-0095-z

Coupe RH, Blomquist JD (2004) Water-soluble pesticides in finished water of community water supplies. J Am Water Works Ass 96:56-68. https://doi.org/10.1002/j.1551-8833.2004. tb10723.x

Cronk JK, Fennesy MS (2001) Wetland plants: biology and ecology. Lewis Publishers, Boca Raton

Crum SJH, Van Kammen-Polman AMM, Leistra M (1999) Sorption of nine pesticides to three aquatic macrophytes. Arch Environ Con Toxicol 37:310-316. https://doi.org/10.1007/ s002449900519

Cui S, Hough R, Yates K et al (2020) Effects of season and sediment-water exchange processes on the partitioning of pesticides in the catchment environment: implications for pesticides monitoring. Sci Total Environ 698:134228. https://doi.org/10.1016/j.scitotenv.2019.134228

Dalton RL, Boutin C, Pick FR (2015) Nutrients override atrazine effects on riparian and aquatic plant community structure in a north American agricultural catchment. Freshw Biol 60:1292-1307. https://doi.org/10.1111/fwb.12563

Davies J, Honegger JL, Tencalla FG et al (2003) Herbicide risk assessment for non-target aquatic plants: sulfosulfuron - a case study. Pest Manag Sci 59:231-237. https://doi.org/10.1002/ps.625

De Baat ML, Bas DA, Van Beusekom SAM et al (2018) Nationwide screening of surface water toxicity to algae. Sci Total Environ 645:780-787. https://doi.org/10.1016/j.scitotenv.2018.07.214

De Baat ML, Kraak MHS, van der Oost R et al (2019) Effect-based nationwide surface water quality assessment to identify ecotoxicological risks. Water Res 159:434-443. https://doi.org/ 10.1016/j.watres.2019.05.040

de Carvalho RF, Bromilow RH, Greenwood R (2007a) Uptake and translocation of non-ionised pesticides in the emergent aquatic plant parrot feather Myriophyllum aquaticum. Pest Manag Sci 63:798-802. https://doi.org/10.1002/ps.1394

de Carvalho RF, Bromilow RH, Greenwood R (2007b) Uptake of pesticides from water by curly waterweed Lagarosiphon major and lesser duckweed Lemna minor. Pest Manag Sci 63:789-797. https://doi.org/10.1002/ps.1389

De Deckere E, De Cooman W, Leloup V et al (2011) Development of sediment quality guidelines for freshwater ecosystems. J Soils Sed 11:504-517. https://doi.org/10.1007/s11368-010-0328-x

De Jong FMW, Brock TCM, Foekema EM, Leeuwangh P (2008) Guidance for summarizing and evaluating aquatic micro- and mesocosm studies. RIVM report 601506009, Bilthoven, The Netherlands, $59 \mathrm{pp}$

De Zwart D, Posthuma L (2005) Complex mixture toxicity for single and multiple species: proposed methodologies. Environ Toxicol Chem 24:2665-2676. https://doi.org/10.1897/04639r.1

Debenest T, Silvestre J, Coste M, Pinelli E (2010) Effects of pesticides on freshwater diatoms. Rev Environ Contam Toxicol 203:87-103. https://doi.org/10.1007/978-1-4419-1352-4_2

Delle Site A (2001) Factors affecting sorption of organic compounds in natural sorbent/ water systems and sorption coefficients for selected pollutants. A review. Phys Chem Ref Data 30:187-439. https://doi.org/10.1063/1.1347984

DeLorenzo ME, Scott GI, Ross PE (2001) Toxicity of pesticides to aquatic microorganisms: a review. Environ Toxicol Chem 20:84-98. https://doi.org/10.1002/etc.5620200108

Devault DA, Pascaline H (2013) Herbicide impact on seagrass communities. In: Price AJ, Kelton JA (eds) Herbicides - current research and case studies in use, InTechOpen, pp 353-375. https:// doi.org/10.5772/55973

Devault DA, Gérino M, Laplanche C et al (2009) Herbicide accumulation and evolution in reservoir sediments. Sci Total Environ 407:2659-2665. https://doi.org/10.1016/j.scitotenv.2008.12.064

Devine MD, Bestman HD, Vanden Born WH (1987) Uptake and accumulation of the herbicides chlorsulfuron and clopyralid in excised pea root tissue. Plant Physiol 85:82-86. https://doi.org/ $10.1104 / \mathrm{pp} .85 .1 .82$ 
Dhir B, Sharmila P, Pardha Saradhi P (2009) Potential of aquatic macrophytes for removing contaminants from the environment. Crit Rev Environ Sci Technol 39:754-781. https://doi. org/10.1080/10643380801977776

Diepens NJ, Arts GH, Focks A, Koelmans AA (2014a) Uptake, translocation, and elimination in sediment-rooted macrophytes: a model-supported analysis of whole sediment test data. Environ Sci Technol 48:12344-12353. https://doi.org/10.1021/es503121x

Diepens NJ, Arts GHP, Brock TCM et al (2014b) Sediment toxicity testing of organic chemicals in the context of prospective risk assessment: a review. Crit Rev Environ Sci Technol 44:255-302. https://doi.org/10.1080/01496395.2012.718945

EFSA PPR (2018) Scientific Opinion on the state of the art of Toxicokinetic/Toxicodynamic (TKTD) effect models for regulatory risk assessment of pesticides for aquatic organisms. EFSA Journal 16(8):5377

EFSA PPR (European Food Safety Authority Panel on Plant Protection Products and their Residues) (2013) Guidance on tiered risk assessment for plant protection products for aquatic organisms in edge-of-field surface waters. EFSA J 11:3290. https://doi.org/10.2903/j.efsa. 2013.3290

EFSA PPR (European Food Safety Authority Panel on Plant Protection Products and their Residues) (2015) Scientific opinion on the effect assessment for pesticides on sediment organisms in edge-of-field surface water. EFSA J 13:4176. https://doi.org/10.2903/j.efsa.2015.4176

Eggleton J, Thomas KV (2004) A review of factors affecting the release and bioavailability of contaminants during sediment disturbance events. Environ Int 30:973-980. https://doi.org/10. 1016/j.envint.2004.03.001

Eklund BT, Kautsky L (2003) Review on toxicity testing with marine macroalgae and the need for method standardization-exemplified with copper and phenol. Mar Pollut Bull 46:171-181. https://doi.org/10.1016/S0025-326X(02)00225-4

Ensminger MP, Budd R, Kelley KC, Goh KS (2013) Pesticide occurrence and aquatic benchmark exceedances in urban surface waters and sediments in three urban areas of California, USA, 2008-2011. Environ Monit Assess 185:3697-3710. https://doi.org/10.1007/s10661-012-2821-8

Fahl GM, Kreft L, Altenburger R et al (1995) pH-dependent sorption, bioconcentration and algal toxicity of sulfonylurea herbicides. Aquat Toxicol 31:175-187. https://doi.org/10.1016/0166445X(94)00067-Z

Fang W, Peng Y, Muir D et al (2019) A critical review of synthetic chemicals in surface waters of the US, the EU and China. Environ Int 131:104994. https://doi.org/10.1016/j.envint.2019. 104994

Faure M, San Miguel A, Ravanel P, Raveton M (2012) Concentration responses to organochlorines in Phragmites australis. Environ Pollut 164:188-194. https://doi.org/10.1016/j.envpol.2012.01.040

Faust M, Altenburger R, Boedeker W, Grimme LH (1993) Additive effects of herbicide combinations on aquatic non-target organisms. Sci Total Environ 134(Suppl 2):941-952. https://doi.org/ 10.1016/S0048-9697(05)80101-9

Feiler U, Kirchesch I, Heininger P (2004) A new plant bioassay for aquatic sediments. J Soil Sediment 4:261266. https://doi.org/10.1007/BF02991122

Feiler U, Ratte M, Arts G et al (2014) Inter-laboratory trial of a standardized sediment contact test with the aquatic plant Myriophyllum aquaticum (ISO 16191). Environ Toxicol Chem 33:662-670. https://doi.org/10.1002/etc.2483

Fernandez RT, Whitwell T, Riley MB, Bernard CR (1999) Evaluating semiaquatic herbaceous perennials for use in herbicide phytoremediation. J Am Soc Hort Sci 124:539-544. https://doi. org/10.21273/JASHS.124.5.539

Fernández D, Vermeirssen ELM, Bandow N, Muñoz K, Schäfer RB (2014) Calibration and field application of passive sampling for episodic exposure to polar organic pesticides in streams. Environ Pollut 194:196-202. https://doi.org/10.1016/j.envpol.2014.08.001

Feurtet-Mazel A, Grollier T, Grouselle M et al (1996) Experimental study of bioaccumulation and effects of the herbicide isoproturon on freshwater rooted macrophytes (Elodea densa and 
Ludwigia natans). Chemosphere 32:1499-1512. https://doi.org/10.1016/0045-6535(96)000586

Förstner U (2004) Sediments - resource of waste. J Soil Sediment 4:3. https://doi.org/10.1007/ BF02990821

Gao Y, Fang J, Zhang J et al (2011) The impact of the herbicide atrazine on growth and photosynthesis of seagrass, Zostera marina (L.), seedlings. Mar Pollut Bull 62:1628-1631. https://doi.org/10.1016/j.marpolbul.2011.06.014

Gao Y, Fang J, Du M et al (2017) Response of the eelgrass (Zostera marina L.) to the combined effects of high temperatures and the herbicide, atrazine. Aquat Bot 142:41-47. https://doi.org/ 10.1016/j.aquabot.2017.06.005

Ge X, d'Avignon DA, Ackerman JJH, Sammons RD (2014) In vivo P-nuclear magnetic resonance studies of glyphosate uptake, vacuolar sequestration, and tonoplast pump activity in glyphosateresistant horseweed. Plant Physiol 166:1255-1268. https://doi.org/10.1104/pp.114.247197

Ghattas A-K, Fischer F, Wick A, Ternes TA (2017) Anaerobic biodegradation of (emerging) organic contaminants in the aquatic environment. Water Res 116:268-295. https://doi.org/10. 1016/j.watres.2017.02.001

Giddings JM, Brock TCM, Heger W, Heimbach F, Maund SJ, Norman S, Ratte H-T, Schäfers C, Streloke M (2002) Community-level aquatic system studies-interpretation criteria (CLASSIC). SETAC, Pensacola, p 44

Gomes MP, Juneau P (2017) Temperature and light modulation of herbicide toxicity on algal and cyanobacterial physiology. Front Environ Sci 5:50. https://doi.org/10.3389/fenvs.2017.00050

González-Barreiro O, Rioboo C, Herrero C, Cid A (2006) Removal of triazine herbicides from freshwater systems using photosynthetic microorganisms. Environ Pollut 144:266-271. https:// doi.org/10.1016/j.envpol.2005.12.014

Graymore M, Stagnitti F, Allinson G (2001) Impacts of atrazine in aquatic ecosystems. Environ Int 26:483-495. https://doi.org/10.1016/S0160-4120(01)00031-9

Guida M, Inglese M, Meriç S (2008) A multi-battery toxicity investigation on fungicides. Desalination 226:262-270. https://doi.org/10.1016/j.desal.2007.04.096

Guilizzoni P (1991) The role of heavy metals and toxic materials in the physiological ecology of submersed macrophytes. Aquat Bot 41:87-109. https://doi.org/10.1016/0304-3770(91)90040-C

Hampel M, Moreno-Garrido I, Sobrino C et al (2001) Acute toxicity of LAS homologues in marine microalgae: esterase activity and inhibition growth as endpoints of toxicity. Ecotoxicol Environ Safe 48:287-292. https://doi.org/10.1006/eesa.2000.2028

Hanson ML, Sanderson H, Solomon KR (2003) Variation, replication, and power analysis of Myriophyllum spp. microcosm toxicity data. Environ Toxicol Chem 22:1318-1329. https:// doi.org/10.1002/etc.5620220619

Hasenbein S, Peralta J, Lawler SP, Connon RE (2017) Environmentally relevant concentrations of herbicides impact non-target species at multiple sublethal endpoints. Sci Total Environ 607-608:733-743. https://doi.org/10.1016/j.scitotenv.2017.06.270

Haynes D, Müller J, Carter S (2000) Pesticide and herbicide residues in sediments and seagrasses from the great barrier reef world heritage area and Queensland coast. Mar Pollut Bull 41:279-287. https://doi.org/10.1016/S0025-326X(00)00097-7

Heine S, Schmitt W, Schäffer A et al (2015) Mechanistic modelling of toxicokinetic processes within Myriophyllum spicatum. Chemosphere 120:292-298. https://doi.org/10.1016/j. chemosphere.2014.07.065

Hermosin MC, Calderon MJ, Real M, Cornejo J (2013) Impact of herbicides used in olive groves on waters of the Guadalquivir river basin (southern Spain). Agric Ecosyst Environ 164:229-243. https://doi.org/10.1016/j.agee.2012.09.021

Hershner C, Havens KJ (2008) Managing invasive aquatic plants in a changing system: strategic consideration of ecosystem services. Conserv Biol 22:544-550. https://doi.org/10.1111/j.15231739.2008.00957.x

Hill IR, Heimbach F, Leeuwangh P, Matthiessen P (1994) Freshwater field tests for Hazard assessment of chemicals. Chemical Rubber Company Press, Boca Raton 
Hinman ML, Klaine SJ (1992) Uptake and translocation of selected organic pesticides by the rooted aquatic plant Hydrilla verticillata Royle. Environ Sci Technol 26:609-613. https://doi.org/10. 1021/es00027a026

Hsu FC, Kleier DA (1996) Phloem mobility of xenobiotics VIII. A short review. J Exp Bot 47:1265-1271. https://doi.org/10.1093/jxb/47.Special_Issue.1265

Hussner A, Stiers I, Verhofstad MJJM et al (2017) Management and control methods of invasive alien freshwater aquatic plants: a review. Aquat Bot 136:112-137. https://doi.org/10.1016/j. aquabot.2016.08.002

ISO (The International Organization for Standardization) (2005) Water quality - determination of the toxic effect of water constituents and waste water on duckweed (Lemna minor) - Duckweed growth inhibition test. ISO Water quality, 20079

ISO (The International Organization for Standardization) (2010) Water quality - growth inhibition test with the marine and brackish water macroalga Ceramium tenuicorne. ISO Water quality, 10710

ISO (The International Organization for Standardization) (2012) Water quality - fresh water algal growth inhibition test with unicellular green algae. ISO Water quality, 8692

ISO (The International Organization for Standardization) (2013) Water quality - determination of the toxic effect of sediment on the growth behaviour of Myriophyllum aquaticum. ISO Water quality, 16191

ISO (The International Organization for Standardization) (2016) Water quality - marine algal growth inhibition test with Skeletonema sp and Phaeodactylum tricornutum ISO Water quality, 10253

ISO (The International Organization for Standardization) (2017) Water quality - determination of the growth inhibition effects of waste waters, natural waters and chemicals on the duckweed Spirodela polyrhiza - Method using a stock culture independent microbiotest. ISO Water quality, 20227

Jones TW, Winchell L (1984) Uptake and photosynthetic inhibition by atrazine and its degradation products on four species of submerged vascular plants 1. J Environ Qual 13:243-247. https:// doi.org/10.2134/jeq1984.00472425001300020014x

Jones L, Ronan J, McHugh B et al (2015) Emerging priority substances in the aquatic environment: a role for passive sampling in supporting WFD monitoring and compliance. Anal Methods 7:7976-7984. https://doi.org/10.1039/c5ay01059d

Kanissery R, Gairhe B, McAvoy C, Sims G (2019) Herbicide bioavailability determinant processes in the soil. J Bioremed Biodegr 10:458. https://doi.org/10.4172/2155-6199.1000458

Kemp WM, Boynton WR, Cunningham JJ et al (1985) Effects of atrazine and linuron on photosynthesis and growth of the macrophytes, Potamogeton perfoliatus L. and Myriophyllum spicatum L. in an estuarine environment. Mar Environ Res 16:255-280. https://doi.org/10. 1016/0141-1136(85)90023-6

Kettenring KM, Adams CR (2011) Lessons learned from invasive plant control experiments: a systematic review and meta-analysis. J Appl Ecol 48:970-979. https://doi.org/10.1111/j.13652664.2011.01979.x

Klaus J, Zehe E, Elsner M et al (2014) Controls of event-based pesticide leaching in natural soils: a systematic study based on replicated field scale irrigation experiments. J Hydrol 512:528-539. https://doi.org/10.1016/j.jhydrol.2014.03.020

Knauer K (2016) Pesticides in surface waters: a comparison with regulatory acceptable concentrations (RACs) determined in the authorization process and consideration for regulation. Environ Sci Eur 28:13. https://doi.org/10.1186/s12302-016-0083-8

Knauer K, Vervliet-Scheebaum M, Dark RJ, Maund SJ (2006) Methods for assessing the toxicity of herbicides to submersed aquatic plants. Pest Manag Sci 62:715-722. https://doi.org/10.1002/ps. 1226

Knauer K, Mohr S, Feiler U (2008) Comparing growth development of Myriophyllum spp. in laboratory and field experiments for ecotoxicological testing. Environ Sci Pollut Res 15:322-331. https://doi.org/10.1007/s11356-008-0008-1 
Knauer K, Homazava N, Junghans M, Werner I (2017) The influence of particles on bioavailability and toxicity of pesticides in surface water. Integr Environ Assess Manag 2017:585-600. https:// doi.org/10.1002/ieam.1867

Knauert S, Singer H, Hollender J, Knauer K (2010) Phytotoxicity of atrazine, isoproturon, and diuron to submersed macrophytes in outdoor mesocosms. Environ Pollut 158:167-174. https:// doi.org/10.1016/j.envpol.2009.07.023

Knuteson SL, Whitwell T, Klaine SJ (2002) Influence of plant age and size on simazine toxicity and uptake. J Environ Qual 31:2096-2103. https://doi.org/10.2134/jeq2002.2096

Kookana RS, Baskaran SNR, Naidu R (1998) Pesticide fate and behaviour in Australian soils in relation to contamination and management of soil and water: a review. Aust J Soil Res 36:715-764. https://doi.org/10.1071/S97109

Kottuparambil S, Lee S, Han T (2013) Single and interactive effects of the antifouling booster herbicides diuron and Irgarol 1051 on photosynthesis in the marine cyanobacterium, Arthrospira maxima. Toxicol Environ Health Sci 5:71-81. https://doi.org/10.1007/s13530013-0157-6

Kronvang B, Laubel A, Larsen SE, Friberg N (2003) Pesticides and heavy metals in Danish streambed sediment. Hydrobiologia 494:93-101. https://doi.org/10.1023/A:1025441610434

Kumar KS, Han T (2011) Toxicity of single and combined herbicides on PSII maximum efficiency of an aquatic higher plant, Lemna sp. Toxicol Environ Health Sci 3:97-105. https://doi.org/10. 1007/s13530-011-0084-3

Lake EC, Minteer CR (2018) A review of the integration of classical biological control with other techniques to manage invasive weeds in natural areas and rangelands. BioControl 63:71-86. https://doi.org/10.1007/s10526-017-9853-5

Lamoureux EM, Brownawell BJ (1999) Chemical and biological availability of sediment-sorbed hydrophobic organic contaminants. Environ Toxicol Chem 18:1733-1741. https://doi.org/10. 1002/etc.5620180818

Landrum PF, Fisher SW (1998) Influence of lipids on the bioaccumulation and trophic transfer of organic contaminants in aquatic organisms. In: Arts MT, Wainman BC (eds) Lipids in freshwater ecosystems. Springer, New York, pp 203-234. https://doi.org/10.1007/978-1-4612-0547$0 \_10$

Landrum PF, Harkey GA, Kukkonen J (1996) Evaluation of organic contaminant exposure in aquatic organisms: the significance of bioconcentration and bioaccumulation. In: Newman MC, Jagoe CH (eds) Ecotoxicology - a hierarchical treatment. Lewis Publishers, Ann Arbor, pp $85-127$

Leu C, Singer H, Stamm C, Müller SR, Schwarzenbach RP (2004) Variability of herbicide losses from 13 fields to surface water within a small catchment after a controlled herbicide application. Environ Sci Technol 38:3835-3841. https://doi.org/10.1021/es0499593

Leusch FDL, Khan SJ, Laingam S et al (2014) Assessment of the application of bioanalytical tools as surrogate measure of chemical contaminants in recycled water. Water Res 49:300-315. https://doi.org/10.1016/j.watres.2013.11.030

Lewis MA, Weber DE, Stanley RS, Moore JC (2001) The relevance of rooting vascular plants as indicators of estuarine sediment quality. Arch Environ Con Toxicol 40:25-34. https://doi.org/ 10.1007/s002440010145

Lockhart WL, Billeck BN, Baron CL (1989) Bioassays with a floating aquatic plant (Lemna minor) for effects of sprayed and dissolved glyphosate. Hydrobiologia 188:353-359. https://doi.org/10. 1007/BF00027800

Loos R, Gawlik BM, Locoro G et al (2009) EU-wide survey of polar organic persistent pollutants in European river waters. Environ Pollut 157:561-568. https://doi.org/10.1016/j.envpol.2008.09. 020

Lopez B, Ollivier P, Togola A et al (2015) Screening of French groundwater for regulated and emerging contaminants. Sci Total Environ 518-519:562-573. https://doi.org/10.1016/j. scitotenv.2015.01.110 
Lorenz S, Rasmussen JJ, Süß A et al (2017) Specifics and challenges of assessing exposure and effects of pesticides in small water bodies. Hydrobiologia 793:213-224. https://doi.org/10. 1007/s10750-016-2973-6

Lovett-Doust J, Schmidt M, Lovett-Doust L (1994) Biological assessment of aquatic pollution: a review, with emphasis on plants as biomonitors. Biol Rev 69:147-186. https://doi.org/10.1111/ j.1469-185X.1994.tb01504.x

Macinnis-Ng CMO, Ralph PJ (2004) In situ impact of multiple pulses of metal and herbicide on the seagrass, Zostera capricorni. Aquat Toxicol 67:227-237. https://doi.org/10.1016/j.aquatox. 2004.01.012

Magnusson M, Heimann K, Quayle P, Negri AP (2010) Additive toxicity of herbicide mixtures and comparative sensitivity of tropical benthic microalgae. Mar Pollut Bull 60:1978-1987. https:// doi.org/10.1016/j.marpolbul.2010.07.031

Magnusson M, Heimann K, Ridd M, Negri AP (2013) Pesticide contamination and phytotoxicity of sediment interstitial water to tropical benthic microalgae. Water Res 47:5211-5221. https://doi. org/10.1016/j.watres.2013.06.003

Malaj E, von der Ohe PC, Grote M et al (2014) Large-scale risk assessment of organic chemicals. Proc Natl Acad Sci 111:9549-9554. https://doi.org/10.1073/pnas.1321082111

Maltby L, Arnold D, Arts G et al (2009) Aquatic Macrophyte risk assessment for pesticides. Society of Environmental Toxicology and Chemistry Press \& Chemical Rubber Company Press, Boca Raton, pp 1-162

Masiá A, Campo J, Vázquez-Roig P et al (2013) Screening of currently used pesticides in water, sediments and biota of the Guadalquivir River basin (Spain). J Hazard Mater 263:95-104. https://doi.org/10.1016/j.jhazmat.2013.09.035

Massei R, Busch W, Wolschke $\mathrm{H}$ et al (2018) Screening of pesticide and biocide patterns as risk drivers in sediments of major European river mouths: ubiquitous or river basin-specific contamination? Environ Sci Technol 524:2251-2260. https://doi.org/10.1021/acs.est.7b04355

Mercurio P, Mueller JF, Eaglesham G et al (2016) Degradation of herbicides in the tropical marine environment: influence of light and sediment. PLoS One 11:e0165890. https://doi.org/10.1371/ journal.pone. 0165890

Moore MT, Locke MA (2012) Phytotoxicity of atrazine, s-metolachlor, and permethrin to Typha latifolia (Linneaus) germination and seedling growth. Bull Environ Contam Toxicol 89:292-295. https://doi.org/10.1007/s00128-012-0682-z

Moore MT, Huggett DB, Huddleston GM, Rodgers JH, Cooper CM (1999) Herbicide effects on Typha latifolia (Linneaus) germination and root and shoot development. Chemosphere 38:3637-3647. https://doi.org/10.1016/S0045-6535(98)00561-X

Moschet C, Wittmer I, Simovic J et al (2014) How a complete pesticide screening changes the assessment of surface water quality. Environ Sci Technol 48:5423-5432. https://doi.org/10. 1021/es500371t

Moser A, Wemyss D, Scheidegger R et al (2018) Modelling biocide and herbicide concentrations in catchments of the Rhine basin. Hydrol Earth Syst Sci 22:4229-4249. https://doi.org/10.5194/ hess-22-4229-2018

Muller S, Huggett D, Rodgers J Jr (2001) Effects of copper sulfate on Typha latifolia seed germination and early seedling growth in aqueous and sediment exposures. Arch Environ Contam Toxicol 40:192-197. https://doi.org/10.1007/s002440010163

Müller R, Shinn C, Waldvogel AM et al (2019) Long-term effects of the fungicide pyrimethanil on aquatic primary producers in macrophyte-dominated outdoor mesocosms in two European ecoregions. Sci Total Environ 665:982-994. https://doi.org/10.1016/j.scitotenv.2019.02.050

Munz N, Melo L, Reyes M et al (2017) Pesticides drive risk of micropollutants in wastewater impacted streams during low flow conditions. Water Res 110:366-377. https://doi.org/10.1016/ j.watres.2016.11.001

Mynampati KC, Lee YJ, Wijdeveld A et al (2015) RhizoFlowCell system reveals early effects of micropollutants on aquatic plant rhizosphere. Environ Pollut 207:205-210. https://doi.org/10. 1016/j.envpol.2015.08.047 
Neale PA, Munz NA, Aït-Aïssa S et al (2017) Integrating chemical analysis and bioanalysis to evaluate the contribution of wastewater effluent on the micropollutant burden in small streams. Sci Total Environ 576:785-795. https://doi.org/10.1016/j.scitotenv.2016.10.141

Netherland MD (2014) Chemical control of aquatic weeds. In: Gettys L, Haller W, Petty D (eds) Biological control of aquatic plants: a best management practices handbook, 3rd edn. Aquatic Ecosystem Restoration Foundation, Michigan, pp 71-88

OECD (Organization for Economic Cooperation, Development and Growth) (2006a) OECD terrestrial plant test: seedling emergence and seedling growth test. OECD guidelines for the testing of chemicals, 208

OECD (Organization for Economic Cooperation, Development and Growth) (2006b) OECD Lemna growth inhibition test. OECD guidelines for the testing of chemicals, 221

OECD (Organization for Economic Cooperation, Development and Growth) (2006c) Guidance document on simulated freshwater lentic field tests (outdoor microcosms and mesocosms). Series on testing and assessment, no 53, ENV/JM/MONO(2006)17, OECD Environment Directorate, Paris, $37 \mathrm{pp}$

OECD (Organization for Economic Cooperation, Development and Growth) (2011) OECD freshwater alga and cyanobacteria, Growth inhibition test. OECD guidelines for the testing of chemicals, 201

OECD (Organization for Economic Cooperation, Development and Growth) (2014a) OECD sediment-free Myriophyllum spicatum toxicity test. OECD guidelines for the testing of chemicals, 238

OECD (Organization for Economic Cooperation, Development and Growth) (2014b) OECD watersediment Myriophyllum spicatum toxicity test. OECD guidelines for the testing of chemicals, 239

Olette R, Couderchet M, Biagianti S, Eullaffroy P (2008) Toxicity and removal of pesticides by selected aquatic plants. Chemosphere 70:1414-1421. https://doi.org/10.1016/j.chemosphere. 2007.09.016

Pandey P, Caudill J, Lesmeister S et al (2019) Assessing glyphosate and fluridone concentrations in water column and sediment leachate. Front Environ Sci 7:22. https://doi.org/10.3389/fenvs. 2019.00022

Plant and Soil Sciences eLibrary (2019) https://passel.unl.edu

Pérez DJ, Okada E, Menone ML, Costa JL (2017) Can an aquatic macrophyte bioaccumulate glyphosate? Development of a new method of glyphosate extraction in Ludwigia peploides and watershed scale validation. Chemosphere 185:975-982. https://doi.org/10.1016/j.chemosphere. 2017.07.093

Pipe AE, Cullimore DR (1984) Influence of five phenylurea herbicides on the diatom Hantzschia in a sandy loam soil. Bull Environ Contam Toxicol 33:439-443. https://doi.org/10.1007/ BF01625567

Rabodonirina S, Net S, Ouddane B et al (2015) Distribution of persistent organic pollutants (PAHs, Me-PAHs, PCBs) in dissolved, particulate and sedimentary phases in freshwater systems. Environ Pollut 206:38-48. https://doi.org/10.1016/j.envpol.2015.06.023

Ralph PJ, Smith RA, Macinnis-Ng CMO, Seery CR (2007) Use of fluorescence-based ecotoxicological bioassays in monitoring toxicants and pollution in aquatic systems: review. Toxicol Environ Chem 89:589-607. https://doi.org/10.1080/02772240701561593

Ramezani M, Oliver DP, Kookana RS, Gill G, Preston C (2008) Abiotic degradation (photodegradation and hydrolysis) of imidazolinone herbicides. J Environ Sci Health B 43:105-112. https://doi.org/10.1080/03601230701794968

Rämö RA, Van den Brink PJ, Ruepert C, Castillo LE, Gunnarsson JS (2018) Environmental risk assessment of pesticides in the river Madre de Dios, Costa Rica using PERPEST, SSD, and msPAF models. Environ Sci Pollut Res 25:13254-13269. https://doi.org/10.1007/s11356-0167375-9 
Rasmussen JJ, Wiberg-Larsen P, Baattrup-Pedersen A et al (2015) The legacy of pesticide pollution: an overlooked factor in current risk assessments of freshwater systems. Water Res 84:25-32. https://doi.org/10.1016/j.watres.2015.07.021

Ratte M, Ratte H (2014) Myriophyllum toxicity test: result of a ring test using M. aquaticum and M. spicatum grown in a water-sediment system. OECD Environment, Health and Safety Publications (EHS), series on testing and assessment, no. 206, OECD Publishing, Paris

Reilly TJ, Smalling KL, Orlando JL, Kuivila KM (2012) Occurrence of boscalid and other selected fungicides in surface water and groundwater in three targeted use areas in the United States. Chemosphere 89:228-234. https://doi.org/10.1016/j.chemosphere.2012.04.023

Remucal CK (2014) The role of indirect photochemical degradation in the environmental fate of pesticides: a review. Environ Sci Process Impacts 16:628-653. https://doi.org/10.1039/ C3EM00549F

Rice PJ, Anderson TA, Coats JR (2004) Effect of sediment on the fate of metolachlor and atrazine in surface water. Environ Toxicol Chem 23:1145-1155. https://doi.org/10.1897/03-110

Roessink I, Belgers JDM, Crum SJH et al (2006) Impact of triphenyltin acetate in microcosms simulating floodplain lakes. II. Comparison of species sensitivity distributions between laboratory and semi-field. Ecotoxicology 15:411-424. https://doi.org/10.1007/s10646-006-0063-7

Scarlett A, Donkin P, Fileman TW, Morris RJ (1999) Occurrence of the antifouling herbicide, irgarol 1051, within coastal-water seagrasses from Queensland, Australia. Mar Pollut Bull 38:687-691. https://doi.org/10.1016/S0025-326X(99)00003-X

Schneiders GE, Koeppe MK, Naidu MV et al (1993) Fate of rimsulfuron in the environment. J Agric Food Chem 41:2404-2410. https://doi.org/10.1021/jf00036a036

Schreiner VC, Szöcs E, Bhowmik AK et al (2016) Pesticide mixtures in streams of several European countries and the USA. Sci Total Environ 573:680-689. https://doi.org/10.1016/j. scitotenv.2016.08.163

Schroer AFW, Belgers JDM, Brock TCM et al (2004) Comparison of laboratory single species and field population-level effects of the pyrethroid insecticide $\lambda$-cyhalothrin on freshwater invertebrates. Arch Environ Contam Toxicol 46:324-335. https://doi.org/10.1007/s00244-003-2315-3

Semple KT, Doick KJ, Jones KC et al (2004) Peer reviewed: defining bioavailability and bioaccessibility of contaminated soil and sediment is complicated. Environ Sci Technol 38:228A-231A. https://doi.org/10.1021/es040548w

Semple KT, Riding MJ, McAllister LE et al (2013) Impact of black carbon on the bioaccessibility of organic contaminants in soil. J Hazard Mater 261:808-816. https://doi.org/10.1016/j.jhazmat. 2013.03.032

Sherwani SI, Arif IA, Khan HA (2015) Modes of action of different classes of herbicides. In: Price A, Kelton J, Sarunaite L (eds) Herbicides, physiology of action, and safety. IntechOpen, p 23. https://doi.org/10.5772/61779

Singh B, Singh K (2016) Microbial degradation of herbicides. Crit Rev Microbiol 42:245-261. https://doi.org/10.3109/1040841X.2014.929564

Sjollema SB, Vavourakis CD, Van der Geest HG et al (2014) Seasonal variability in irradiance affects herbicide toxicity to the marine flagellate Dunaliella tertiolecta. Front Mar Sci 1:13. https://doi.org/10.3389/fmars.2014.00013

Snel JFH, Vos JH, Gylstra R, Brock TCM (1998) Inhibition of photosystem II (PSII) electron transport as a convenient endpoint to assess stress of the herbicide linuron on freshwater plants. Aquat Ecol 32:113-123. https://doi.org/10.1023/A:1009971930626

Stehle S, Schulz R (2015) Insecticide contamination of global surface waters. Proc Natl Acad Sci 112:5750-5755. https://doi.org/10.1073/pnas.1500232112

Storck FR, Sacher F, Brauch HJ (2015) Hazardous and emerging substances in drinking water resources in the Danube river basin. In: Liska I (ed) The Danube river basin. Springer, Heidelberg. https://doi.org/10.1007/978-3-662-47739-7

Tang J, Hoagland KD, Siegfried BD (1998) Uptake and bioconcentration of atrazine by selected freshwater algae. Environ Toxicol Chem 17:1085-1090. https://doi.org/10.1897/1551-5028 (1998)017\%3C1085:UABOAB\%3E2.3.CO;2 
Tang T, Stamm C, Van Griensven A et al (2017) Hysteresis and parent-metabolite analyses unravel characteristic pesticide transport mechanisms in a mixed land use catchment. Water Res 124:663-672. https://doi.org/10.1016/j.watres.2017.08.016

Thompson PA, Couture P (1991) Short- and long-term changes in growth and biochemical composition of Selenastrum capricornutum populations exposed to cadmium. Aquat Toxicol 21:135-143. https://doi.org/10.1016/0166-445X(91)90068-K

Thorngren JL, Harwood AD, Murphy TM et al (2017) Fate and risk of atrazine and sulfentrazone to nontarget species at an agriculture site. Environ Toxicol Chem 36:1301-1310. https://doi.org/ 10.1002/etc.3664

Traas TP, Van de Meent D, Posthuma L, Hamers T, Kater BJ et al (2002) The potentially affected fraction as a measure of ecological risk. In: Posthuma L, Suter GW II, Traas TP (eds) Species sensitivity distributions in ecotoxicology. Lewis Publishers, Boca Raton, pp 315-344

Tuckey DM, Orcutt DM, Hipkins PLL (2002) Inherent and growth stage-related differences in growth and lipid and sterol composition of algal species sensitive and tolerant to sterolinhibiting fungicides. Environ Toxicol Chem 21:1715-1723. https://doi.org/10.1002/etc. 5620210825

Turgut C (2005) Uptake and modeling of pesticides by roots and shoots of parrotfeather (Myriophyllum aquaticum). Environ Sci Pollut Res 12:342-346. https://doi.org/10.1065/ espr2005.05.256

Turgut C, Fomin A (2002) Sensitivity of the rooted macrophyte Myriophyllum aquaticum (Vell.) Verdcourt to seventeen pesticides determined on the basis of $\mathrm{EC}_{50}$. B Environ Contam Toxicol 69:601-608. https://doi.org/10.1007/s00128-002-0103-9

USEPA (United States Environmental Protection Agency) (2012a) Algal toxicity. USEPA ecological effects test guidelines, 850.4500

USEPA (United States Environmental Protection Agency) (2012b) Aquatic plants field study. USEPA ecological effects test guidelines, 850.4450

USEPA (United States Environmental Protection Agency) (2012c) Aquatic plant toxicity test using Lemna spp. USEPA ecological effects test guidelines, 850.4400

USEPA (United States Environmental Protection Agency) (2012d) Cyanobacteria (Anabaena flosaquae) toxicity. USEPA ecological effects test guidelines, 850.4550

USEPA (United States Environmental Protection Agency) (2012e) Seedling emergence and seedling growth. USEPA ecological effects test guidelines, 850.4100

USEPA (United States Environmental Protection Agency) (2016) Species sensitivity distribution generator. https://www.epa.gov/caddis-vol4/caddis-volume-4-data-analysisdownload-software

Van den Brink PJ, Blake N, Brock TC, Maltby L (2006) Predictive value of species sensitivity distributions for effects of herbicides in freshwater ecosystems. Hum Ecol Risk Assess 12:645-674. https://doi.org/10.1080/10807030500430559

Van Wijngaarden R, Arts GH (2018) Is the tier-1 effect assessment for herbicides protective for aquatic algae and vascular plant communities? Environ Toxicol Chem 37:175-183. https://doi. org/10.1002/etc.3936

Vijver MG, van 't Zelfde M, Tamis WLM et al (2008) Spatial and temporal analysis of pesticides concentrations in surface water: pesticides atlas. J Environ Sci Health B 43:665-674. https://doi. org/10.1080/03601230802388728

Voice TC, Weber WJ Jr (1983) Sorption of hydrophobic compounds by sediments, soils and suspended solids - I. Theory and background. Water Res 17:1433-1441. https://doi.org/10. 1016/0043-1354(83)90275-0

Vonk JA, Benigni R, Hewitt M et al (2009) The use of mechanisms and modes of toxic action in integrated testing strategies: the report and recommendations of a workshop held as part of the European Union OSIRIS integrated project. ATLA-Altern Lab Anim 37:557-571. https://doi. org/10.1177/026119290903700512

Vrana B, Allan IJ, Greenwood R et al (2005) Passive sampling techniques for monitoring pollutants in water. TrAC Trends Anal Chem 24:845-868. https://doi.org/10.1016/j.trac.2005.06.006 
Wang P, Liu X, Wu X et al (2018) Evaluation of biochars in reducing the bioavailability of flubendiamide in water/sediment using passive sampling with polyoxymethylene. J Hazard Mater 344:1000-1006. https://doi.org/10.1016/j.jhazmat.2017.12.003

Weiner JA, DeLorenzo ME, Fulton MH (2004) Relationship between uptake capacity and differential toxicity of the herbicide atrazine in selected microalgal species. Aquat Toxicol 68:121-128. https://doi.org/10.1016/j.aquatox.2004.03.004

Whatley MH, Van Loon EE, Van Dam H et al (2014) Macrophyte loss drives decadal change in benthic invertebrates in peatland drainage ditches. Freshw Biol 59:114-126. https://doi.org/10. $1111 /$ fwb. 12252

Wilkinson AD, Collier CJ, Flores F et al (2015) A miniature bioassay for testing the acute phytotoxicity of photosystem II herbicides on seagrass. PLoS One 10(2):e0117541. https:// doi.org/10.1371/journal.pone.0117541

Wilson PC, Wilson SB (2010) Toxicity of the herbicides bromacil and simazine to the aquatic macrophyte, Vallisneria americana Michx. Environ Toxicol Chem 29:201-211. https://doi.org/ $10.1002 /$ etc. 22

Wilson PC, Wilson SB (2011) Characterization of selected organo-nitrogen herbicides in South Florida canals: exposure and risk assessments. Sci Total Environ 412-413:119-126. https://doi. org/10.1016/j.scitotenv.2011.09.058

Wittmer IK, Bader H-P, Scheidegger R et al (2010) Significance of urban and agricultural land use for biocide and pesticide dynamics in surface waters. Water Res 44:2850-2862. https://doi.org/ 10.1016/j.watres.2010.01.030

Wood RJ, Mitrovic SM, Lim RP, Kefford BJ (2016) How benthic diatoms within natural communities respond to eight common herbicides with different modes of action. Sci Total Environ 557-558:636-643. https://doi.org/10.1016/j.scitotenv.2016.03.142

Wu F, Gao Y, Zuo Z et al (2020) Different decreasing rates of chemical threshold concentrations can be explained by their toxicokinetic and toxicodynamic characteristics. Sci Total Environ 708:135234. https://doi.org/10.1016/j.scitotenv.2019.135234

Zhang W (2018) Global pesticide use: Profile, trend, cost/benefit and more. P Int Acad Ecol Environ Sci 8(1):1-27

Open Access This chapter is licensed under the terms of the Creative Commons Attribution 4.0 International License (http://creativecommons.org/licenses/by/4.0/), which permits use, sharing, adaptation, distribution and reproduction in any medium or format, as long as you give appropriate credit to the original author(s) and the source, provide a link to the Creative Commons licence and indicate if changes were made.

The images or other third party material in this chapter are included in the chapter's Creative Commons licence, unless indicated otherwise in a credit line to the material. If material is not included in the chapter's Creative Commons licence and your intended use is not permitted by statutory regulation or exceeds the permitted use, you will need to obtain permission directly from the copyright holder.

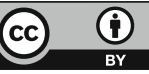

